\title{
The contribution of small-scale, privately owned tropical aquaculture to food security and dietary diversity in Bolivia
}

\author{
Sean Irwin ${ }^{1,2}$ (D) $\cdot$ Mark S. Flaherty $^{1} \cdot$ Joachim Carolsfeld ${ }^{3}$ \\ Received: 4 November 2019 / Accepted: 4 September 2020 / Published online: 12 October 2020 \\ (C) The Author(s) 2020
}

\begin{abstract}
New aquaculture systems are emerging in new contexts around the world in part due to aquaculture's perceived development benefits. However, linkages between aquaculture and food security in these systems are unclear. This study investigated the impact of emerging small-scale, business-oriented fish culture in central Bolivia on the food security and dietary diversity of aquaculture producers $(n=40)$ and workers $(n=26)$ in the value chain and compared them to local non-aquaculture farmers $(n=$ 40). Three pathways were investigated: fish consumption, household income, and women's participation. Food insecurity was widespread and did not vary in a statistically significant way between groups, but a trend toward greater food security amongst aquaculture producers was observed. Dietary diversity was highly homogenous, with the notable exception of high fish consumption amongst producers. Aquaculture was related to higher income, and income has a modest positive effect on food security for aquaculturists and non-aquaculture farmers, but not aquaculture value chain workers. Income did not have an effect on dietary diversity. Women's involvement in aquaculture was correlated positively to productivity, profitability, and size of operation, while male-only aquaculture was negatively correlated to these. The value chain generated employment, especially for women, but average wages were higher for men. The research provides important insight into aquaculture-food security linkages by showing that the introduction of small-scale business-oriented aquaculture systems can provide nutritious products for regional consumption and can have positive effects on food security but is not sufficient to change local dietary preferences more broadly.
\end{abstract}

Keywords Aquaculture $\cdot$ Food security $\cdot$ Dietary diversity $\cdot$ women's participation $\cdot$ Value chain $\cdot$ Bolivia

\section{Introduction}

Aquaculture is the world's fastest-growing food-production system, currently contributing over half of the total global fish and seafood supply (FAO 2020). This is driving aquaculture expansion into new regions, which is leading to the diversification of species, farming methods and environments used (FAO 2020; Metian et al. 2020). This growth and diversification has contributed to global aquaculture revenues of $\$ 263.6$ billion and the provision of livelihoods to 20.5 million people,

Sean Irwin

sean.1irwin@royalroads.ca

1 Department of Geography, University of Victoria, Victoria, BC, Canada

2 School of Business, Royal Roads University, Victoria, BC, Canada

3 World Fisheries Trust, Victoria, BC, Canada
$19 \%$ of whom are women, and mostly with small-scale systems (FAO 2020). Aquaculture's contribution to food security is both through income and through the provision of food that is considered particularly nutritious (Bene et al. 2016; Mohanty et al. 2017).

The sector's exponential growth and contributions to income and food security, however, has not been even across countries, income groups, gender, or ethnicity. In 2017 Asia was responsible for over $91 \%$ of total aquaculture production, and high value industrial production is a feature of most other top producing regions (Tacon 2020). Thus, such systems disproportionately contribute to the ongoing discourse about global aquaculture production and its future prospects (Garlock et al. 2020). Small scale aquaculture in emerging regions is substantially different, but continues to be promoted in many developing countries and through the general rhetoric on aquaculture productivity as a pathway to poverty reduction, improved food security, and healthier diets (Bene et al. 2015, 2016; Marinda et al. 2018; Mohanty et al. 2017; Thilsted et al. 
2016). There are many differences that can influence the actual contribution of aquaculture to local food security and income, as well as the participation by women and other marginalized communities (Bene et al. 2016; Bush et al. 2019; Filipski and Belton 2018; Kruijssen et al. 2018). Improved characterization of the impacts of this level of aquaculture, in different contexts, is required to improve its use in sustainable and equitable development.

The Plurinational State of Bolivia is one of the poorest and most food insecure countries in Latin America (EIU 2018; World Bank 2018). Despite recent advances (Telesur 2017; World Bank 2019a), Bolivia continues to face serious food and nutrition challenges (World Food Programme 2018). In the 2018 Global Hunger Index, Bolivia ranks 65th out of 119 countries (Global Hunger Index 2018). In 2016 just over $16 \%$ of children under the age of five suffered from stunting (World Bank 2019b). According to the World Food Programme, access is the main cause of food insecurity in Bolivia as incomes are low and often insufficient to meet basic food needs (World Food Programme 2018). This is particularly the case with the largely rural and indigenous population that depends heavily on low productivity, semi-subsistence agriculture (Rapsomaniskis 2015).

Bolivia lags far behind neighboring countries in aquaculture development and has one of the of the lowest rates of fish consumption in the world (Camburn 2011). This is despite lowland Bolivia having a high potential for fish culture (Valladao et al. 2016; Vega et al. 2018). Recently, a nucleus of aquaculture is expanding in the corridor between Santa Cruz de la Sierra and Cochabamba based on NGO and government support for small-scale private-enterprise oriented farm diversification. In 2017, Bolivia promulgated the Sustainable Fisheries and Aquaculture Law to, in part, promote further aquaculture development in this area (PPV2 2017).

This paper examines the food security impacts of the private enterprise oriented central Bolivian aquaculture system on value chain participants. The analysis of value chains has emerged as an effective approach to understanding the development impact of economic activities, including the food security impacts of aquaculture (Allen and de Brauw 2018; Belton et al. 2015; Donovan et al. 2015; Fanzo et al. 2017). Three pathways identified by Kawarazuka and Bene (2010) were investigated: direct impacts from increased fish consumption, indirect impacts through household income, and the impact on the economic status of women.

The paper is organized as follows. Section 2 presents details on the central Bolivian aquaculture system and the methods used in the study. Section 3 presents the results of the analysis, grouped according to the three pathways between aquaculture and food security mentioned above. Section 4 discusses how the results are situated in the literature and the key insights derived.
Section 5 concludes with a summary of the study, key findings, and policy recommendations.

\section{Research context and methods}

\subsection{The central Bolivian aquaculture value chain and study area}

Tropical aquaculture development in Bolivia has mostly focused on pond culture of the indigenous omnivorous fish known locally as "tambaqui" (Piaractus brachypomus) and "pacu" (Colossoma macropomum), or their hybrids (Valladao et al. 2016; Vega et al. 2018). These fish are robust and easy to grow, and are high in essential amino acids, unsaturated fatty acids, iron, and protein (Murthy et al. 2015; Petenuci et al. 2016). The fish were identified by the FAO as a promising native alternative to tilapia culture in the late 1970s, and its culture has been perfected in Brazil and neighboring countries. It is now one of the top producing aquaculture species in South America, serving domestic markets with primarily small to medium sized farms and competing favorably with the salmon and tilapia export industries (Valladao et al. 2016).

This fish culture was first introduced into the study area by Gabriel Rene Moreno University, which initiated a core of medium-sized growers around Santa Cruz de la Sierra (FAO 2005). Some of these are now the prime local providers of fingerlings and feed. NGO-led aid projects in other parts of Bolivia, in parallel to the university effort, focused on indigenous communities, as well as lower income farmers to dissuade coca growing. Most of these had a focus on communal ownership and did not continue operating once international subsidies ended (Canal-Beeby 2012). A legacy of interest in the activity and some technical capacity remained, but only a few initiatives by more affluent farmers and/or subsidized by municipalities continued. Some subsistence level initiatives that focused on carp culture and supported by religiousbased organizations also continued (Canal-Beeby 2012; FAO 2005). In the 2000s, the non-profit organization Centro de Promoción Agropecuaria Campesina (CEPAC), with Spanish international development funding, promoted fish culture as part of their portfolio of farm diversification activities focused on opportunities for women. This initiative was then continued through support from the Canadian-funded Peces para la Vida (PPV) projects, which contributed to the resurgence of this kind of fish culture in central Amazonian Bolivia.

We found the central Bolivian aquaculture value chain (CBAVC) to be short and relatively simplistic in comparison to those in many other developing countries (see Ponte et al. 2014 for examples). The primary reason is that the CBAVC is highly territorially fixed. There is very little distribution of fish 
into other regions of the country, and no international exports. As well, the sector's small size does not provide a sufficiently large enough market to support many intermediary businesses such as processing, transport, or brokerage. For the most part, key nodes in the chain interact directly with one another instead of being mediated by institutions or firms. That said, some fish farmers, as well as a few feed and fingerling suppliers, occasionally mediate feed and fish distribution. The four key nodes are input firms, producers, retailers, and consumers, with fish buyers and feed distributors being occasionally present. All aquaculture production in the CBAVC is small to medium sized in scale, consisting of familymanaged farms that sell to local retailers and consumers. There are no large-scale corporate and/or industrial operations. Input suppliers are small to medium sized privatelyowned businesses and are few in number. Markets for aquaculture products are primarily local food markets and restaurants. Informal sales from producers directly to consumers occur but are not routine. The CBAVC is presented in Fig. 1.

Producers in the CBAVC operate in the central lowlands of Bolivia in an area that straddles the eastern portion of the Department of Cochabamba, and the western portion of the Department of Santa Cruz. This region is part of Bolivia's agricultural heartland and is densely populated with small and medium scale land owning farmers. It also has some of the highest numbers of multidimensionally poor households in the country (Andersen 2018). Common agricultural commodities on the Santa Cruz Department side are beef and dairy cattle, rice, soy, and sugar cane. The Cochabamba side, which is more forested, produces cattle and rice as well, but also fruits such as bananas, citrus, and pineapple. Coca is the most common crop on the Cochabamba side, where up to $1600 \mathrm{~m}^{2}$ can be legally farmed for traditional uses. The study area is in proximity to the highway that links the major cities of Santa Cruz de la Sierra and Cochabamba (Fig. 2). Input firms are located in the production region and in the city of Santa Cruz de la Sierra. Retailers and consumers are also located in the production region, with some located in the cities of Santa Cruz de la Sierra and Cochabamba.

The primary fish being farmed commercially in the CBAVC are the native tambaqui and the biologically similar and also native pacu. A few other native and introduced species are also produced, but typically only for household consumption. According to the most recent Bolivian National Agricultural Census (INE 2014), 1463 (0.8\%) of farming households in Cochabamba Department (which includes both highland and lowland regions) are engaged in aquaculture. Of those, $136(9.3 \%)$ produced pacu and 334 (22.8\%) produced tambaqui (INE 2014). In Santa Cruz Department, all of which is lowland, $1065(0.9 \%)$ of farming households practice aquaculture. Of these, 567 (53.2\%) produce pacu and 92 (8.6\%) produce tambaqui. The two departments combined account for $56 \%$ of all aquaculture producers, $76 \%$ of all pacu producers, and $82 \%$ of all tambaqui producers in the country (INE 2014). The high concentration of aquaculture in this area can be attributed to several factors that include favorable environmental conditions (land and soil conducive to pond construction, appropriate climate for fish, water availability), NGO and local governmental support, a culture and history of food production and fishing, and widespread small-scale land ownership (Van Damme et al. 2014).

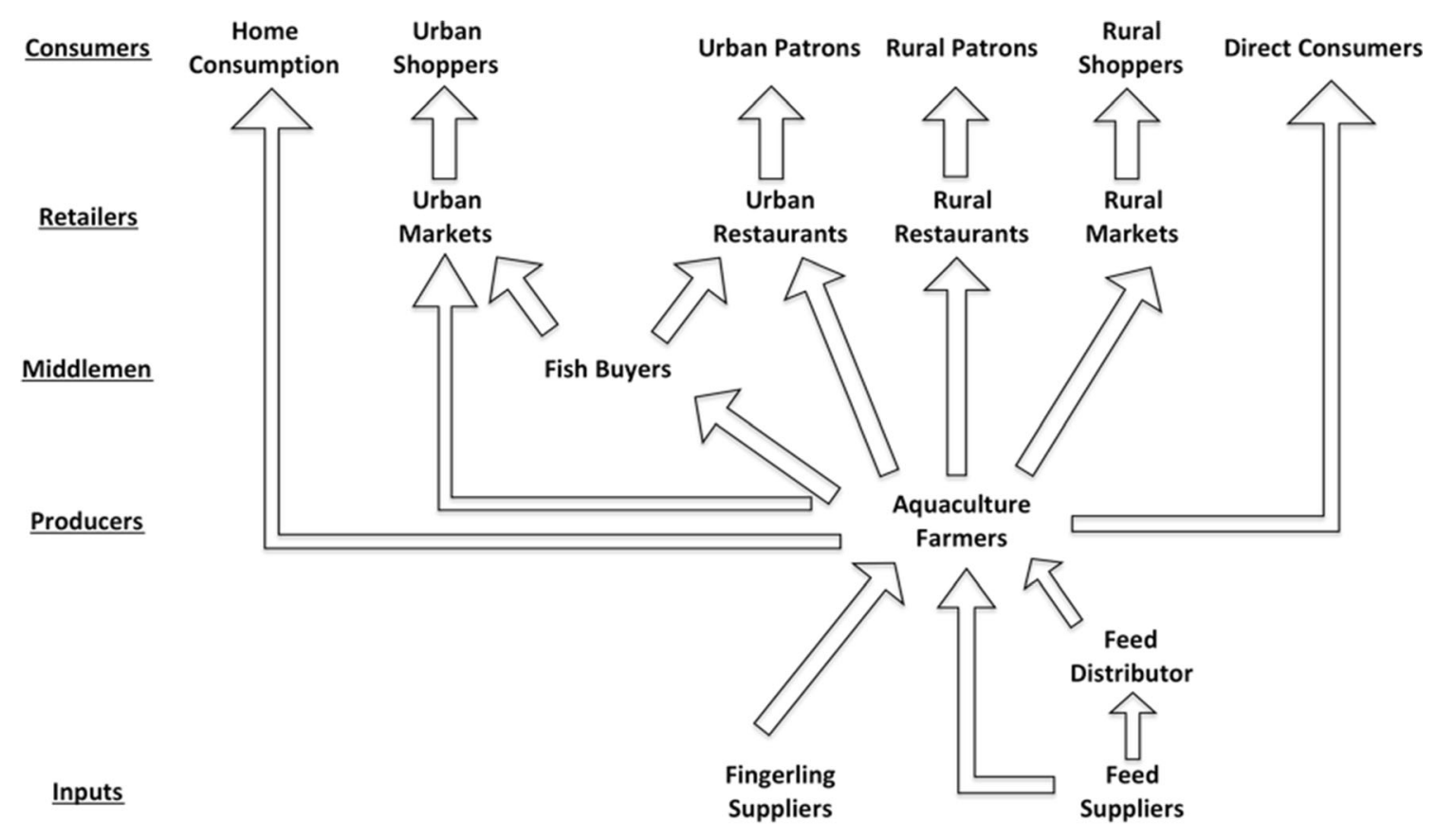

Fig. 1 Actors, value adding nodes, and process flows of the central Bolivian aquaculture value chain 


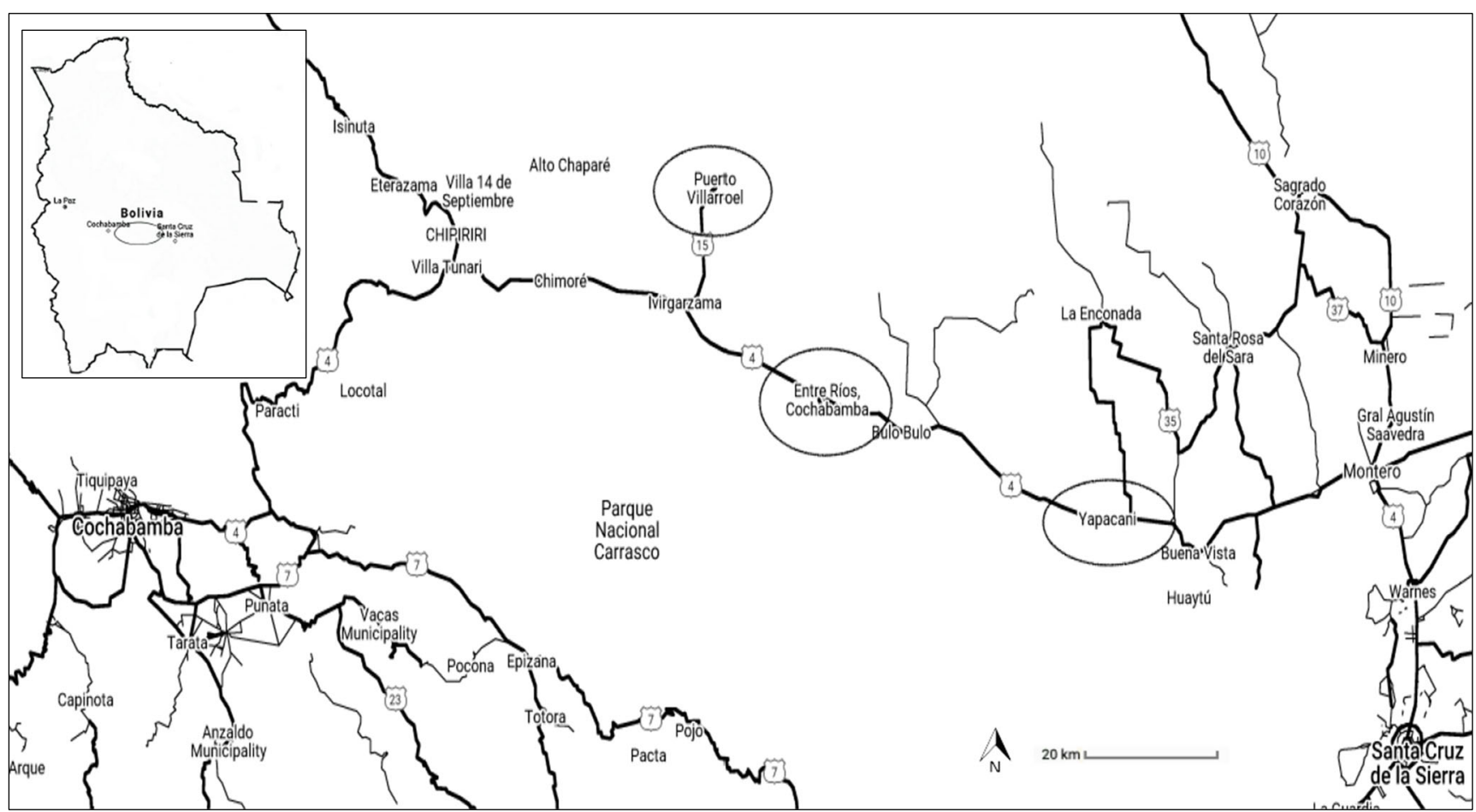

Fig. 2 Map of aquaculture value chain study region in central Bolivia and location of studied municipalities

\subsection{Research participants and sampling}

We interviewed CBAVC producers, workers, and key informants. Producers are small to medium scale commercially oriented farm owners who have aquaculture in their household livelihood portfolio. Some communal ownership projects also exist in the area, as mentioned above, but these projects currently make a relatively small contribution to the local market and were not included in the study. Workers included fish market vendors, servers and cooks in restaurants that serve farmed fish, aquaculture input business workers, and fish farm labourers. Key informants consisted of aquaculture producer association leaders, aquaculture input business owners, owners of restaurants that primarily serve farmed fish, fish market managers, and a professor whose research focuses on central Bolivian aquaculture. We also interviewed farming households who did not engage in aquaculture, but who were neighbors of aquaculture producers, to obtain insight into whether they differed in terms of their social and economic characteristics, from those households that had adopted aquaculture. Table 1 shows a breakdown of interviewees by group, the value chain node that they operate in, and by the gender of the respondent.

Aquaculture producers were selected from a master list of aquaculture farming families $(n=196)$ in three municipalities where the majority of the CBAVC production occurs: Yapacani, Entre Rios, and Puerto Villarroel (Fig. 1). The list was created by Centro de Promoción Agropecuaria Campesina (CEPAC), a local NGO and partner in the Peces para la Vida II project, from membership lists provided by the aquaculture producer associations. Such producer associations are ubiquitous in Bolivia. Almost all farmers are members of associations related to the products that they grow commercially. Each producer on the list was assigned a number with potential interviewees subsequently selected using a random number generator. Interviews were conducted with an available adult representative of the household, regardless of their gender, at their home or in a public place. None of the producers who were contacted declined to be interviewed.

Non-aquaculture producing households were selected through convenience sampling. This approach was adopted as we were interested in obtaining a sample of farmers who were likely aware of aquaculture as a livelihood opportunity, and who also owned land that was suitable for aquaculture, but had not adopted it. Interviewers visited farms that were near the selected aquaculture producers and asked if they farmed fish. If they did not, they were invited to participate. Interview refusals were uncommon. Occasionally interviewees were willing but busy, so arrangements were made to meet at another time. While convenience sampling provided quick and inexpensive access to farmers who were not engaged in aquaculture, we acknowledge that the results may not be representative of the entire population of nonadopters in the region.

Aquaculture value chain workers were also selected by convenience sampling due to time and financial constraints. Owners or managers of aquaculture businesses were asked if it would be possible to interview their workers on site. Informed 
Table 1 Livelihood activities and gender of central Bolivian research participants

\begin{tabular}{llll}
\hline & $n$ & Value chain node of activity & Gender of respondent \\
\hline Aquaculture producers & 40 & Production (40) & 12 women \\
& & & 28 men \\
Value chain workers & 26 & Retail (17) & 16 women \\
& & Production (4) & 10 men \\
Key informants & \multirow{2}{*}{17} & Inputs (5) & Research (1) \\
& & Retail (8) & 5 women \\
& & Production (3) & 12 men \\
Non-aquaculture producers & 40 & Inputs (5) & \\
& & None & 15 women \\
& & & 25 men
\end{tabular}

consent was then obtained from the workers themselves. Interview refusals were uncommon. Key informants were selected using a snowball sampling approach (Neuman 2006). Interviews took place at the interviewee's place of work, home, or in a public space, and none declined to be interviewed.

The interview team consisted of the principal author and a local facilitator who was well-known in the region as a college instructor, former municipal councilor, and life-long resident. Informed consent was obtained from all interviewees prior to the interviews. The questionnaire and methodology were approved by the Human Research Ethics Board at the University of Victoria (\#15-461).

\subsection{Data collection}

Each of the target groups were administered questionnaires tailored to their respective livelihood contexts. The questionnaires consisted of structured questions coupled with open ended qualitative questions. Field research was undertaken from January to April 2016.

Data on income from aquaculture was collected by asking respondents to list the buyers of their fish, how many they sold to each buyer, and for what price. To ensure accuracy, the figures were compared to their responses regarding how many fingerlings they stocked, how many fish they ate at home, and how many fish they lost. The cost of feed, fingerlings, and labour was then subtracted from the gross income to yield their net income. Aquaculture producers were also asked if anyone in the household had off-farm income, and if so, from where and how much per week. Income data for other farmbased livelihood activities was not collected due to the large additional time requirement. Non-aquaculture producer income data was collected by asking respondents to list their income sources and to then discuss the quantity of each product they sold and at what price. If they mentioned an off-farm income activity, they were asked to indicate their weekly salary. Aquaculture and non-aquaculture farm income data was collected based on the most recent complete production cycle. Value chain workers were asked to give their weekly salary or their hourly wage and the number of hours per week that they work.

To investigate women's participation, producers were asked about who was responsible for eight aquaculture production tasks and who made decisions about adopting and expanding aquaculture. The list of tasks involved in aquaculture production was established through consultation with Bolivian project partners and aquaculture experts prior to field work. Key informants were also asked what roles women have in the CBAVC and what roles they would like to see women have.

To investigate overall food security, we used the Escala Latinoamericana y Caribena de Seguridad Alimentaria (ELCSA) (ELCSA 2012). The ELCSA is adapted for Latin America from the Household Food Insecurity Access Scale (Coates et al. 2007). It asks questions that fall into three domains: anxiety about access to food, changes in quality of food, and changes in quantity of food. The scale consists of fifteen questions; the first eight pertain to adults in the household and the last seven to children. All the questions are yes/ no. One point is given for each "yes" response. The sum of the points indicates the severity of food insecurity in the household. A score of 0 indicates a household is food secure. A score of 1-3 for adult only households or 1-5 if there are children in the household indicates mild food insecurity. Mild food insecurity is from when there is anxiety and concern about food supplies up to when adjustments are made in the household budget that affect the quality of diet. A score of 4-6 for adult only or 6-10 for households with children indicates moderate food insecurity. Moderate food insecurity is from when adjustments are made in the household budget that affect the quality of diet up to when adults limit the quality and quantity of food they consume. A score of 7-8 (no children) or 11-15 (with children) indicates severe food insecurity. Severe 
food insecurity is from when adults limit the quality and quantity of food they consume up to when the quality and quantity of food consumed by children is also affected. The different score ranges reflect the extra questions that are added that ask specifically about children in the household (ELCSA 2012). The suggested recall period, which was used in this study, is three months. None of our respondents indicated that they had any difficulty recalling their food security condition over that time period.

In addition to assessing food security, we also investigated dietary diversity. This type of metric captures the number of different kinds of food or food groups that people eat. We used the Household Dietary Diversity Score (HDDS), developed by FANTA (Swindale and Bilinsky 2006) and modified by the FAO (Kennedy et al. 2011). Like the ELCSA, it provides an indicator of access to food, but unlike the ELCSA, it serves as a proxy for the utilization of food by estimating dietary quality, including macro and micro nutrient adequacy. The data are representative of both the household and individual respondents. It asks respondents to detail everything eaten in the household during the previous day. Each food or ingredient is placed into one of twelve equally weighted food groups. The total number of food groups that is represented in the diet gives the Dietary Diversity Score. The ELCSA and the HDDS were administered to all participant groups except the key informants.

\subsection{Data analysis}

Descriptive statistics were generated using Microsoft Excel 2019 and inferential statistics were generated using MINITAB 19. Mean, median, standard deviation (St. Dev.), and co-efficient of variation (C.V.) were used to describe the surveyed respondent groups. Non-parametric methods were used for comparative statistical tests since the data did not meet assumptions of normality. Mann-Whitney U test was used to compare two groups and Kruskal-Wallis ANOVA was used to compare three groups. Spearman's rho was used to determine rank correlation. The statistical significance level used for all tests was $p<0.05$. As with all correlation analyses, there is a possibility of confounding variables, but none were clearly apparent. This study was exploratory in nature and has a small sample size. This was due to the small populations of aquaculture producers and workers, since the CBAVC itself is small. The results should be interpreted accordingly. All income figures are reported in United States Dollars (USD) equivalence of Bolivian currency (Bolivianos-BOB). Bolivia has an exchange rate fixed to the USD of $6.9 \mathrm{BOB}=1 \mathrm{USD}$.

\section{Results}

The results are organized into three sections based on the three pathways between aquaculture and increased food security identified by Kawarazuka and Bene (2010); direct effects of fish consumption, aquaculture's effect on income, and women's participation. Each section has subsections that inform the pathway.

\subsection{Direct food security effects and fish consumption}

This sub-section examines the overall food security (ELCSA) and dietary diversity (HDDS) of respondents. It also reports the frequency of their fish consumption.

\subsubsection{Respondent household food security}

The ELCSA was carried out with aquaculture producers, nonproducers, and chain workers (Table 2). The majority of households in all groups faced some degree of food insecurity. The primary source of food insecurity is anxiety over access to food. Twenty-five $(62.5 \%)$ producer households, thirty-two (80\%) non-producer households, and twenty (77\%) workers answered yes to the first ELCSA question: "in the last three months, due to lack of money or other resources, have you worried that food could run out in your home?" Affirmative responses to the remaining questions regarding recent food choices were less frequent.

According to a Kruskal-Wallis test there was no significant difference in food security between the three groups $(\mathrm{H}=$ $4.04, p=0.13)$. However, Table 2 indicates a likely trend that aquaculture producers are more food secure than nonproducers or workers, which could become more statistically significant with a larger sample size and after a longer engagement in aquaculture. Considering this likely direction, producers had the highest percentage of mildly food insecure households, they also had the highest number of food secure households, and the lowest number of moderately and severely food insecure households. Only $20 \%$ of aquaculture producer households were moderately or severely food insecure, whereas non-aquaculture farming households and worker households are almost twice as likely to be either moderately or severely food insecure (37.5\% and $38.4 \%$ respectively).

\subsubsection{Respondent dietary diversity}

The household dietary diversity questionnaire was administered to all aquaculture producers, non-aquaculture farmers, and aquaculture value chain workers. The result from the Kruskal-Wallis (Table 3 ) indicates that there is no significant difference in dietary diversity between the three groups. Aquaculture producer households score only slightly higher on the HDDS than non-aquaculture farming households who, in turn, had only slightly higher scores than aquaculture value chain workers. Farming fish has had, at best, a very modest effect on improving dietary diversity, other than by increasing 
Table 2 Details of food security levels of respondent groups, as indicated by the Escala Latinoamericana y Caribena de seguridad alimentaria (ELCSA)

\begin{tabular}{|c|c|c|c|}
\hline Category & $\begin{array}{l}\text { AQ } \\
\text { Producers } \\
n=40\end{array}$ & $\begin{array}{l}\text { Non- } \\
\text { Producers } \\
n=40\end{array}$ & $\begin{array}{l}\text { Chain } \\
\text { Workers } \\
n=26\end{array}$ \\
\hline Households that are food secure & $9(22.5 \%)$ & $5(12.5 \%)$ & $3(11.5 \%)$ \\
\hline Households with mild food insecurity & $23(57.5 \%)$ & $20(50 \%)$ & $13(50 \%)$ \\
\hline Households with moderate food insecurity & $4(10 \%)$ & $8(20 \%)$ & $7(26.9 \%)$ \\
\hline Households with severe food insecure & $4(10 \%)$ & $7(17.5 \%)$ & $3(11.5 \%)$ \\
\hline Households that are food insecure & $31(77.5 \%)$ & $35(87.5 \%)$ & $13(88.5 \%)$ \\
\hline $\begin{array}{l}\text { Average degree of food insecurity (scale of } 0-3,0=\text { food } \\
\text { secure, } 1=\text { mild, } 2=\text { moderate, } 3=\text { severe) }\end{array}$ & 1.08 & 1.43 & 1.39 \\
\hline
\end{tabular}

home consumption of fish, in comparison to the other livelihoods considered.

The maximum value for the HDDS is 12. A high HDDS, however, is not necessarily nutritionally positive or desirable (Swindale and Bilinsky 2006). The score is believed to indicate economic access to food, not the degree to which households have a healthy or unhealthy diet (ibid.). The responses to the individual questions that make up the HDDS, however, can shed some light on the nutritional status of households, and whether there are any differences between the three groups. The percentage of households in each group that consumed a food item from each HDDS category is presented in Table 4. According to the Kruskal-Wallis tests, "fish and other seafood" and "fruit" were the only categories where there was a significant difference in consumption between groups. Aquaculture producers consumed the most fish, likely due to on-farm access. Fruit consumption was substantially higher amongst non-aquaculture farmers likely because many grow fruits as part of their livelihood portfolio. Other differences were less significant but indicated trends. Aquaculture chain workers consumed fish more frequently than non-aquaculture producing farmers, likely due to the fact that they would have easier, and perhaps less costly, access to fish. The foods widely considered to be "unhealthy," represented by the categories of "sweets", and "spices, condiments, and beverages", were common across all three groups. Aquaculture producers consumed more sweets than the other two groups, possibly due to their higher income. Aquaculture chain workers consumed more spices, condiments, and beverages than the other groups.

Table 3 Statistical analysis of household dietary diversity score (HDDS) of respondent groups

\begin{tabular}{lllll}
\hline Group & Mean & Median & St. Dev. & C.V. \\
\hline Aquaculture producers & 7.68 & 8 & 1.25 & $16.3 \%$ \\
Non-aquaculture farmers & 7.58 & 8 & 1.30 & $17.2 \%$ \\
Aquaculture value chain workers & 7.46 & 7 & 1.30 & $17.4 \%$ \\
Kruskal-Wallis H=0.6 $(p=0.74)$ & & & & \\
\hline
\end{tabular}

This is likely because nine (35\%) work at restaurants and eight $(31 \%)$ work at markets, giving them easy access to such items.

We observed that households in all three groups prepare very similar meals. Breakfast was simple, consisting of tea and bread. Lunch and dinner were often either a mixed soup or a plate with rice, meat, and a few vegetables. Soup was a particularly central component of this standard diet, with likely an underestimated consumption as it was not specifically polled. A search for "soup" in the data revealed that $75 \%$ of aquaculture producer households, $80 \%$ of non-producer households, and $58 \%$ of chain worker households had reported consuming it the previous day. Some households had consumed it twice in the same day. Local soups usually consist of a thin broth with rice, noodles, and a small amount of vegetables and meat. Processed and packaged foods were not mentioned, nor were dishes that are associated with outside ethnic groups (Chinese, Indian, Italian, etc.).

\subsubsection{Respondent fish consumption}

As outlined in Table 4, aquaculture producers had consumed more fish at home the day before being interviewed than the two other groups. To further gauge aquaculture producer consumption, they were asked how much of the fish that they produce is consumed at home. The total number of fish from the last harvest that was consumed by all producers was 10,485 (8.3\% of the harvest). The total number of fish that an individual household claimed to have consumed ranged from 30 to 1500 , but averaged 262, with the median being 145. Fish was clearly an important part of the diets of most producer households.

While higher fish consumption may be expected for aquaculture producers, it is important to understand how the growth of the aquaculture system is affecting fish consumption in the wider population. Non-aquaculture producers can serve as proxies for consumers generally, and rural aquaculture production region consumers specifically. They were asked questions about their fish consumption habits and preferences, the details of which are in Table 5. Every non- 
Table 4 Proportion of households from each respondent group that consumed an item in each Household Dietary Diversity Score food category and measurement of difference between groups

\begin{tabular}{|c|c|c|c|c|c|}
\hline \multirow[b]{2}{*}{ HDDS Food Category } & \multicolumn{3}{|c|}{ Respondent Group } & \multirow[b]{2}{*}{$\begin{array}{l}\text { Kruskal - } \\
\text { Wallis H }\end{array}$} & \multirow[b]{2}{*}{$\begin{array}{l}p \\
\text { value }\end{array}$} \\
\hline & $\begin{array}{l}\text { Aquaculture } \\
\text { producers }\end{array}$ & $\begin{array}{l}\text { Non-aquaculture } \\
\text { farmers }\end{array}$ & $\begin{array}{l}\text { Aquaculture chain } \\
\text { workers }\end{array}$ & & \\
\hline Cereals & $100 \%$ & $100 \%$ & $100 \%$ & 0 & 1.0 \\
\hline White tubers and roots & $95 \%$ & $93 \%$ & $92 \%$ & 0.27 & 0.88 \\
\hline Vegetables & $95 \%$ & $98 \%$ & $100 \%$ & 1.44 & 0.49 \\
\hline Fruit & $40 \%$ & $80 \%$ & $54 \%$ & 13.36 & 0.001 \\
\hline Meat & $90 \%$ & $90 \%$ & $92 \%$ & 0.12 & 0.94 \\
\hline Eggs & $35 \%$ & $40 \%$ & $23 \%$ & 2.02 & 0.36 \\
\hline Fish and other seafood & $38 \%$ & $13 \%$ & $19 \%$ & 7.23 & 0.03 \\
\hline $\begin{array}{l}\text { Legumes, nuts and } \\
\text { seeds }\end{array}$ & $70 \%$ & $68 \%$ & $58 \%$ & 1.11 & 0.57 \\
\hline Milk and milk products & $30 \%$ & $30 \%$ & $46 \%$ & 2.26 & 0.32 \\
\hline Oils and fats & $38 \%$ & $25 \%$ & $23 \%$ & 2.12 & 0.35 \\
\hline Sweets & $80 \%$ & $65 \%$ & $69 \%$ & 2.30 & 0.32 \\
\hline $\begin{array}{l}\text { Spices, condiments, } \\
\text { and beverages }\end{array}$ & $58 \%$ & $58 \%$ & $69 \%$ & 1.12 & 0.57 \\
\hline
\end{tabular}

producer surveyed said that their family ate fish, with a large proportion having done so the previous week. The fish was consumed primarily at home, and sourced either directly from a farmer/fisher or from the market in comparable proportions. Just over half indicated that some of the fish they consumed came from the river, though only five said that this was their sole source of fish. Fishing is a popular recreational activity in rural Bolivia. There are many rivers in the study region, so this is not an unexpected response. However, it does suggest that fish consumption for some people is low simply because they are unlikely to fish regularly.

The respondents were also asked what species of fish they consume (Fig. 3). The three most popular fish are pacu/tambaqui, surubi (Pseudoplatystoma fasciatum), and sabalo (Prochilodus nigricans). Pacu and tambaqui are combined because many people in the study area use their names interchangeably, and both are primarily sourced from aquaculture. Surubi is a common river fish that is widely available in local markets and restaurants. Sabalo is a lower cost fish that is usually imported from Argentina. Reasons for the low frequency of other types of fish are not fully known, but may be related to availability, fish characteristics (bones and/or flavour), or cultural preferences.

Non-producers were also asked what they like and dislike about eating fish. The results are in Fig. 4. A noteworthy finding is that only one person indicated that they liked that fish was nutritious, which may speak to a generally low level of interest or awareness of nutrition when it comes to making food choices. As for dislikes, fish bones was the largest, but it should be noted that many of the people who said they didn't like the bones in fish seemed to be saying so as an afterthought; it didn't seem to be a significant issue for most.
Table 5 Details of fish consumption of non-aquaculture producers $(n=40)$

\begin{tabular}{ll}
\hline Household fish consumption & Results \\
Households that reported eating fish regularly & $40(100 \%)$ \\
Households that ate fish during the previous week & $67.5 \%$ \\
Number of times households ate fish the previous week & Mean 1.8, range 0-8 \\
Location of fish acquisition & \\
Purchased directly from farmer or fisher & $19(47.5 \%)$ \\
Purchased from a market & $16(40 \%)$ \\
Obtained from a river & $22(55 \%)$ \\
Location of fish consumption & \\
Home & $38(95 \%)$ \\
Restaurant & $9(22.5 \%)$ \\
At a friend's home & $2(5 \%)$ \\
\hline
\end{tabular}




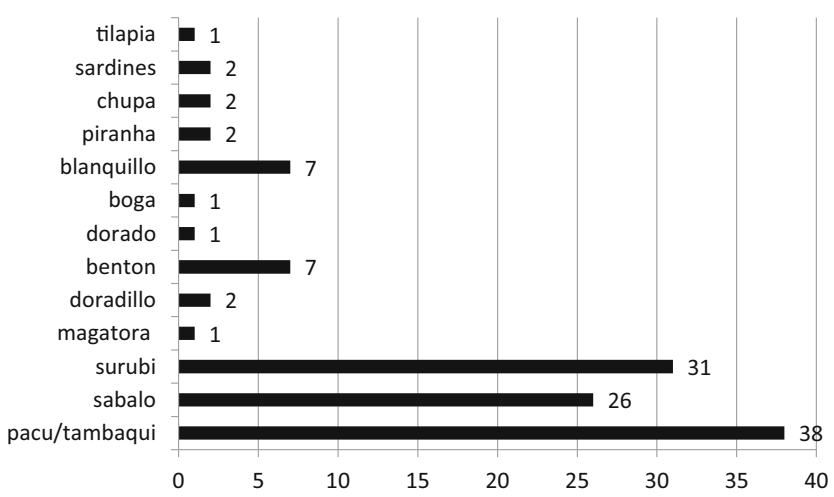

Fig. 3 Number of non-aquaculture producer households that consume regionally available fish species

Respondents were also asked if they would like their family to eat more fish and thirty-six $(90 \%)$ said yes. They were then asked what is stopping them from eating more fish. The responses are in Fig. 5.

The two most frequent responses were that fish is too expensive $(56 \%)$ and that there was no time to fish $(33 \%)$. The first response points to a potential challenge to the growth and spread of aquaculture. The second points to the fact that many people rely on their own fishing for fish to eat at home. Of the four respondents who said their family doesn't want to eat more fish, two said it was because of personal health issues, one said that farmed fish is unhealthy, and the third said that the family already eats a lot.

Based on the HDDS, $19.2 \%$ of value chain workers said they had consumed fish the previous day (Table 4). That was lower than the $37.5 \%$ of producers who had consumed fish the previous day, but higher than the $12.5 \%$ of non-aquaculture producers that said they had consumed fish the previous day. This indicates that fish produced through aquaculture is widely available and is eaten often, but access to fish is a barrier to further increased consumption for some consumers.

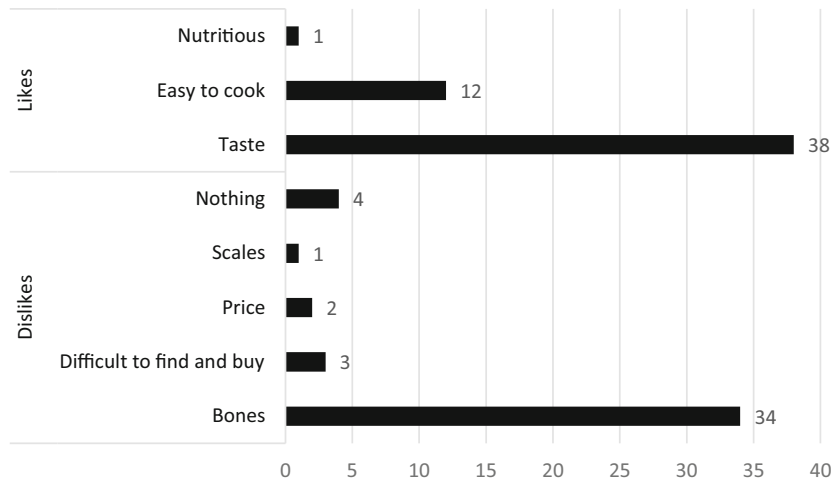

Fig. 4 Response frequencies of what non-aquaculture producers like and dislike about eating fish $(n=40)$

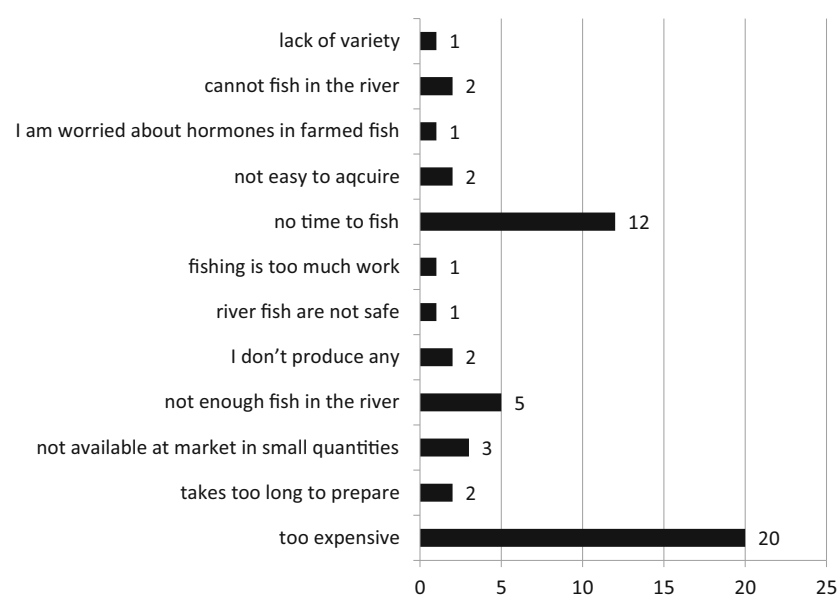

Fig. 5 Response frequencies for why non-aquaculture producer families don't eat more fish $(n=36)$

\subsection{Aquaculture's indirect effect on food security through income}

This sub-section investigates the relationship between income and different food security measures.

\subsubsection{Respondent income}

Aquaculture producer net incomes from aquaculture during the most recent completed production cycle ranged from a loss of $\$ 1254$ USD to a profit of $\$ 39,204$ USD. The mean was $\$ 8219$ USD, the median was \$5594 USD, and the standard deviation was $\$ 9207$ USD. The primary reason for the variability in income is the wide range in the size of aquaculture operations, as measured by $\mathrm{m}^{2}$ of pond. Larger operations can produce more fish which yields more income. The correlation between net income and $\mathrm{m}^{2}$ of stocked pond was strong and significant; Spearman's rho $=0.82, p=0.00$. Net income per $\mathrm{m}^{2}$ of stocked pond ranged from $\$-0.63$ USD to $\$ 3.60$ USD with a mean of $\$ 1.84$ USD and a median of $\$ 1.87$ USD. Three producers had negative net income after the last harvest. The cost of inputs (fingerlings, feed, and labour) per $\mathrm{m}^{2}$ was moderately negatively and significantly correlated to net income per $\mathrm{m}^{2}$ of stocked pond (Spearman's rho $=-0.35, p=0.03$ ). The number of fish lost per $\mathrm{m}^{2}$ of stocked pond was also moderately negatively correlated to net income per $\mathrm{m}^{2}$ of stocked pond (Spearman's rho $=-0.38, p=0.02$ ). Common causes of fish losses are predators, lack of water aeration, and theft. There was no notable correlation between net income per $\mathrm{m}^{2}$ of stocked pond and home fish consumption, training, or number of identified aquaculture production problems. However, there was a moderate correlation with degree of woman's participation, which is outlined in the following section.

Aquaculture producer net income solely from aquaculture was compared to non-producer farmer gross income from all 
of their livelihood activities (Fig. 6). We compare these because they are the most complete figures on the income of each group. Due to time and logistical limitations, producers were not asked detailed questions about the nature of their other livelihood activities. For the same reasons, nonproducers were not asked questions regarding the input costs associated with their livelihood activities. While these two sets of data have some differences, they do provide insight into aquaculture as an income generating activity.

The net income from aquaculture alone that aquaculturists receive is close to the gross income that non-producers receive from all household livelihood activities. In addition, only $20 \%$ of producers indicated that aquaculture was their primary source of income, indicating that aquaculture households generate more income than comparable non-aquaculture households.

The income of workers in the CBAVC is measured as an hourly wage as the number of hours worked per week ranged from 12 to 98 . The average was 60 with a standard deviation of 19.7. The hours of work reported is high because some workers live on site and often work long days and during the weekends. There was a wide range in the hourly wages from $\$ 0.26 \mathrm{USD}$ to $\$ 3.62 \mathrm{USD}$. The average was $\$ 1.25 \mathrm{USD}$ with a median of \$1.14USD, and a standard deviation of $\$ 0.78$ USD. In some cases compensation is underestimated because workers are provided additional support such as room and board. Workers were asked what their previous employment was, and how they would compare it with their current employment. Most previous employment was similar to their current employment except they were now working in some way with fish. The questions and responses are presented in
Table 6. Overall, employment in the CBAVC is perceived to be modestly better than employment in other food value chains.

Entering into aquaculture production as owners is not possible for most CBAVC workers as most lack access to land. Only 3 of the 26 chain workers indicated that they or their immediate family owned land. Most of them lived in a regional town $(n=14,54 \%)$ or city $(n=9,35 \%)$, and only $3(11 \%)$ lived in a rural area.

\subsubsection{Respondent income, food security, and dietary diversity}

The relationship between income and the measures of food security and household dietary diversity for aquaculture producers is presented in Figs. 7 and 8 and for non-aquaculture producers in Figs. 9 and 10, respectively.

Net income from aquaculture was negatively weakly and insignificantly correlated to food insecurity for aquaculture producers. However, the highest income earning aquaculture producer also reported being severely food insecure. If that producer is removed, the correlation becomes stronger $\left(r_{s}=-0.29, p=0.08\right)$. These findings indicate that income has a modest positive effect on improving food security, but that food insecurity is widespread. This is re-enforced by the non-aquaculture producer findings, which show that nonproducer household income is negatively moderately and significantly correlated to food insecurity. With regard to dietary diversity, there is no significant correlation with income for either producers or non-aquaculture producers. The likely reason is that people in the region generally have a very

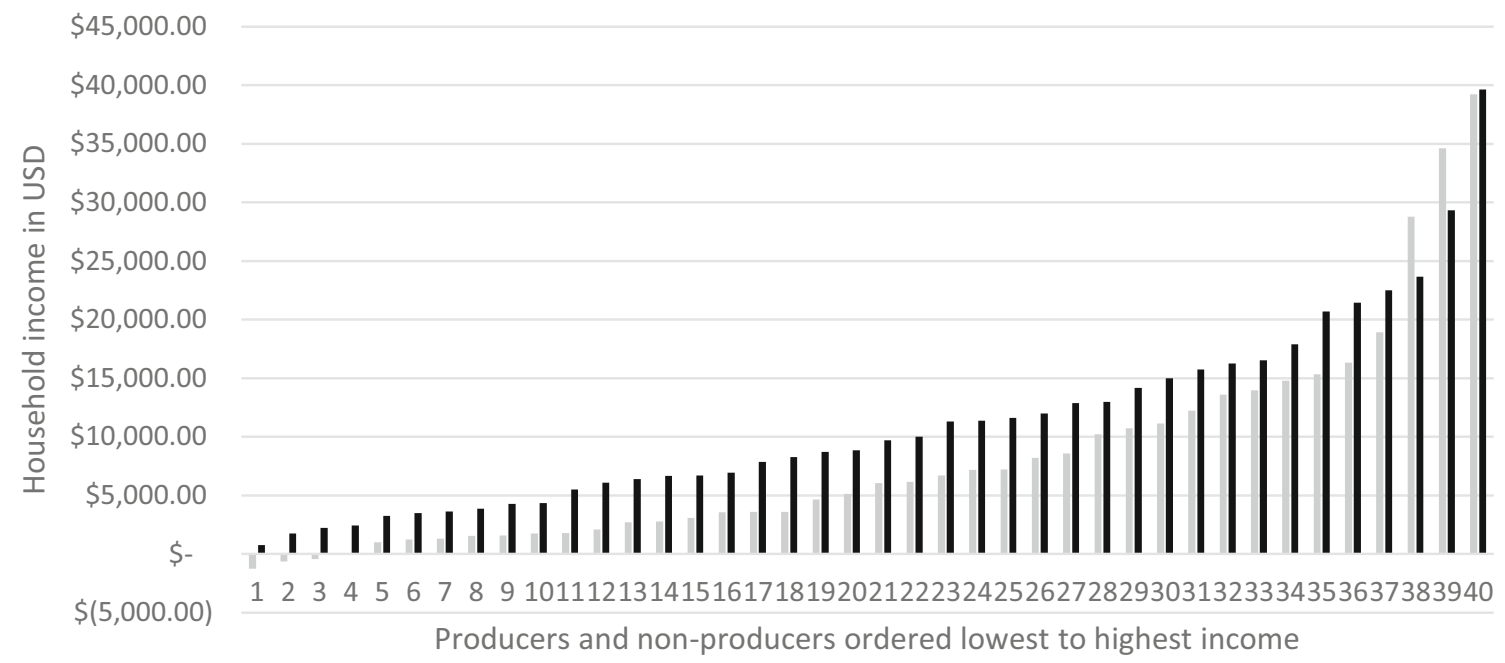

Producer net income solely from aquaculture (USD)

- Non-producer gross income from all household livelihood activities (USD)

Fig. 6 Comparison of aquaculture producer net income solely from aquaculture to non-aquaculture producer gross income from all household livelihoods 
Table 6 Frequency of aquaculture value chain worker responses to questions comparing previous employment to current aquaculture value chain employment

Do you consider the money you make at this job to be a lot less, a little less, the same, a little more, or a lot more than the money you made at your previous job?*

Do you consider the overall quality of this job to be a lot worse, a little worse, the same, a little better, or a lot better than that of your previous job?*

Before you began this job, did you consider yourself to be very poor, poor, not so poor, well off, or rich?

Today, do you consider yourself to be very poor, poor, not so poor, well off, or rich? 0

$\begin{array}{lllll}\begin{array}{l}\text { A lot less } \\ 0\end{array} & \begin{array}{l}\text { A little less } \\ 0\end{array} & \begin{array}{l}\text { The same } \\ 6\end{array} & \begin{array}{l}\text { A little more } \\ 14\end{array} & \begin{array}{l}\text { A lot more } \\ 0\end{array} \\ 0 & 6 & 5 & 12 & 2 \\ \text { Very poor } & \text { Poor } & \text { Not so poor } & \text { Well off } & \text { Rich } \\ 0 & 1 & 6 & 19 & 0 \\ 0 & 0 & 4 & 22 & 0\end{array}$

* one respondent did not answer these questions

homogenous diet that includes a small number of basic foods from the different HDDS categories.

We examined whether the measures of food security and dietary diversity are related to employment income from the CBAVC. As indicated in Figs. 11 and 12, no significant correlations were found. The likely reason is that workers are a heterogeneous low-income group that includes farm hands, feed and fingerling production workers, restaurant servers and cooks, and market workers. Sixteen interviewees who worked $40 \mathrm{~h}$ a week or more were paid less than the national minimum wage of \$261.39 USD per month, before including employment benefits. The size of a worker's family also varies since some workers are young and single while others have families. This heterogeneity is similar to other agricultural occupations; therefore the variability is also likely due to the general prevalence of food insecurity in the region for low income people.

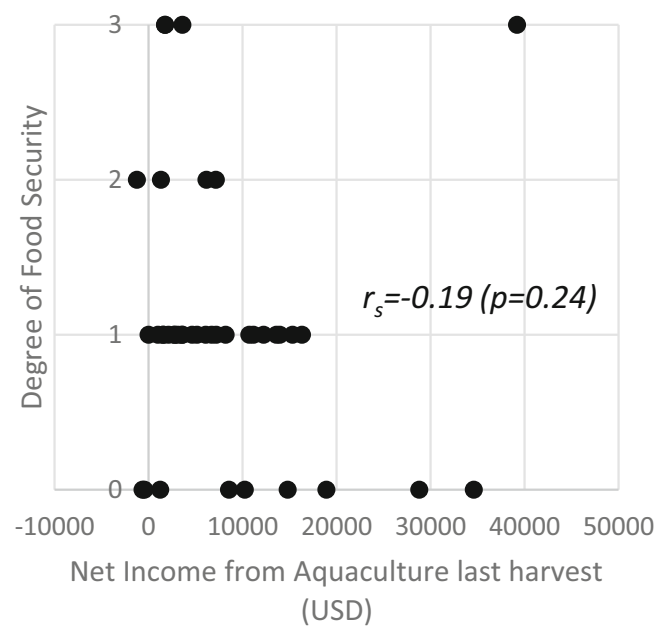

Fig. 7 Relationship between aquaculture net income and degree of food security (Escala Latino Americana y Caribina de seguridad allimentaria scale of $0-3 ; 0=$ food secure, $1=$ mild, $2=$ moderate, $3=$ severe)

\subsection{Women's participation in aquaculture and the effect on food security}

This sub-section outlines the nature of women's participation in aquaculture and presents the effects of such participation.

\subsubsection{Women's participation in the central Bolivian aquaculture value chain}

Producers were asked who in their household had made the decision to start farming fish. It was made by the adult male in ten households, by the adult female in seven households, and by both equally in twenty-three households. Respondents were also asked who was responsible for the tasks associated with aquaculture production. The findings are presented in Table 7.

Men were involved in aquaculture activities more frequently than women. The average number of tasks where men were solely responsible was 3.0 , with a standard

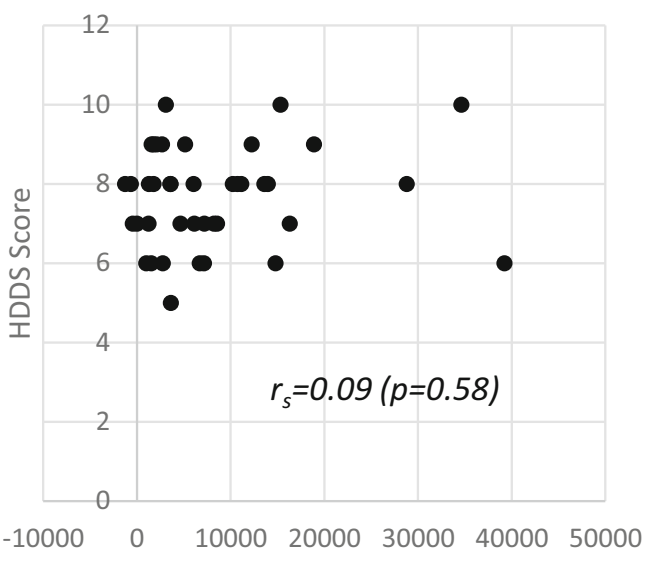

Net Income from Aquaculture last harvest

(USD)

Fig. 8 Relationship between aquaculture net income and household dietary diversity score 


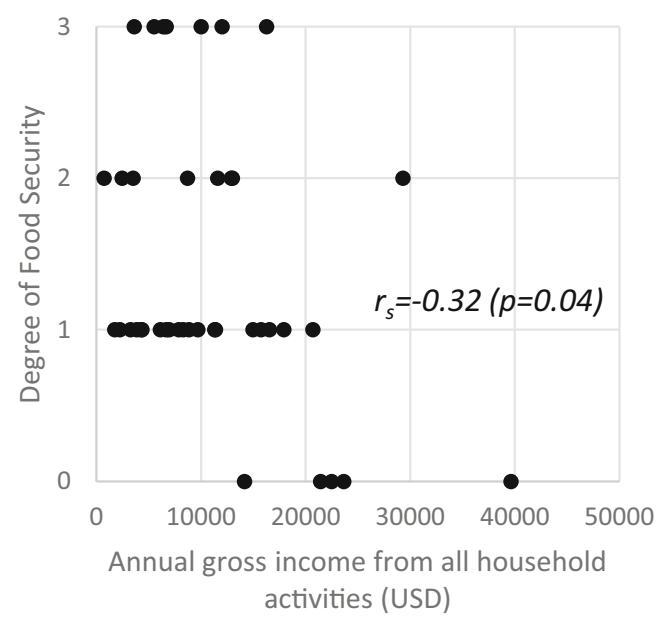

Fig. 9 Relationship between non-aquaculture gross income and degree of food security (Escala Latino Americana y Caribina de seguridad allimentaria scale of $0-3 ; 0=$ food secure, $1=$ mild, $2=$ moderate, $3=$ severe)

deviation of 2.6 whereas the average for women was 1.2 with a standard deviation of 2.0. The average number of tasks that were the responsibility of a woman and a man equally was 4.3 , with a standard deviation of 2.4. The aquaculture production tasks where a woman is solely responsible with the highest frequency are feeding and record keeping. Feeding is high relative to other activities likely because for some households aquaculture is the responsibility of the head woman. Ponds are usually located near the home and since feeding is not labour or time intensive, it dovetails well with many of the other household obligations that women have such as childcare and household management. Maintaining financial records for farm operations is not a widespread practice among small-scale farmers in Bolivia. For those households that kept records it was nearly evenly split between men and women. Record keeping is a task that, unlike most others, appears to be

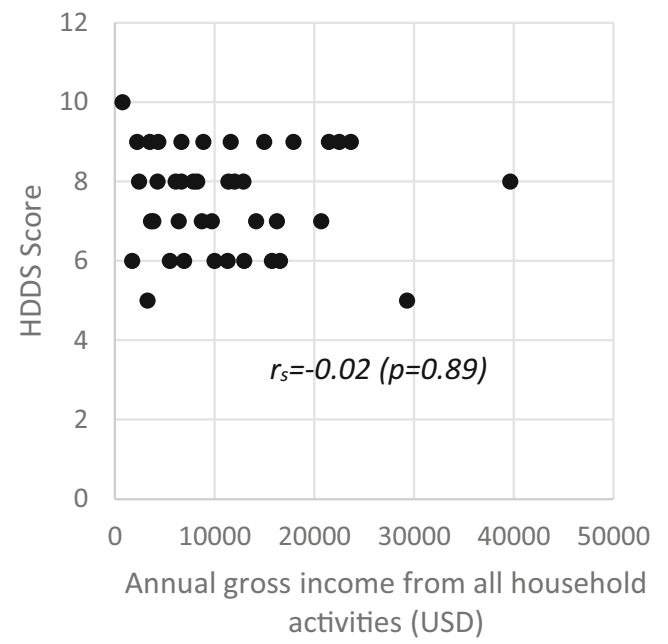

Fig. 10 Relationship between non-aquaculture producer gross income and household dietary diversity score

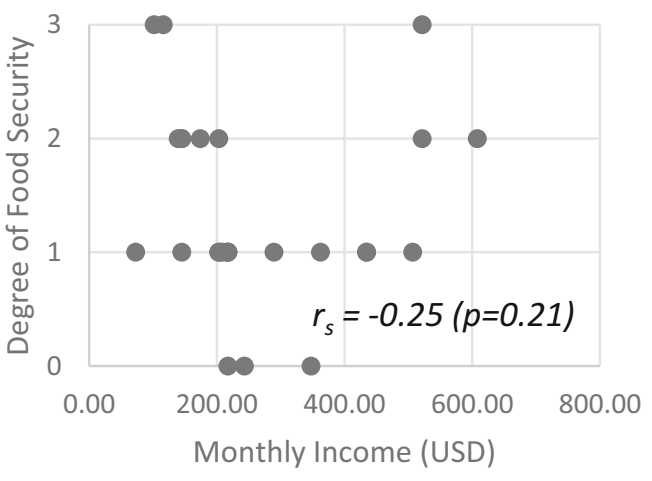

Fig. 11 Relationship between monthly worker income and degree of food security (Escala Latino Americana y Caribina de seguridad allimentaria scale of $0-3 ; 0=$ food secure, $1=$ mild, $2=$ moderate, $3=$ severe)

difficult to share, and is a likely explanation for the near even split.

The tasks where women are responsible equally with men the most frequently are harvesting and processing. These activities occur in tandem over the course of one long day, and often involve not only all household members, but neighbors, friends and occasionally hired workers. The activities in which women are least frequently involved are pond maintenance and fish monitoring. The former is likely due to the fact that pond maintenance is labour intensive and therefore traditionally carried out by men. In the latter case, monitoring usually involves entering the pond, which is something many woman prefer not to do. Overall, only three households indicated that women were not involved in any tasks related to aquaculture.

Employment in the CBAVC is available to both men and women and tends to fall along traditional Bolivian norms of male and female work. Of the twenty-six workers who were interviewed, all of the men $(n=10)$ were either farm hands or supply company labourers and all of the women $(n=16)$ were market or restaurant workers. The former occupations are relatively labour intensive while the latter are less physically demanding.

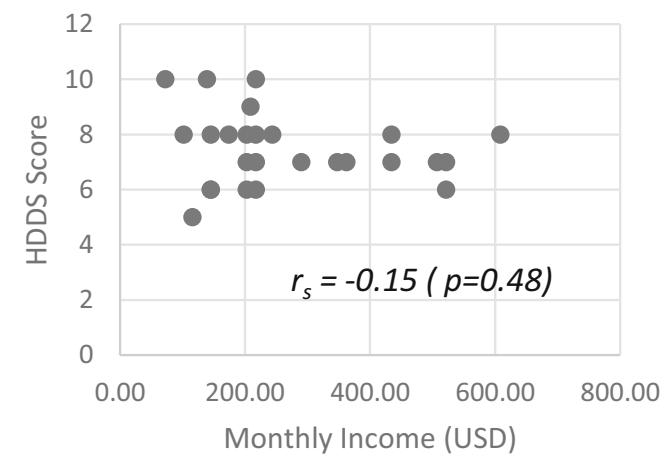

Fig. 12 Relationship between monthly worker income and household dietary diversity score 
Table 7 Aquaculture production activities and the frequencies where they were the responsibility of the head male, head female, or both together

\begin{tabular}{|c|c|c|c|}
\hline Activity & Gender of person responsible & \# & $\%$ \\
\hline \multirow[t]{3}{*}{ Pond construction $n=40$} & Male & 7 & $17.5 \%$ \\
\hline & Female & 5 & $12.5 \%$ \\
\hline & Both & 28 & $70 \%$ \\
\hline \multirow[t]{3}{*}{ Fingerling procurement $n=40$} & Male & 17 & $42.5 \%$ \\
\hline & Female & 5 & $12.5 \%$ \\
\hline & Both & 18 & $45 \%$ \\
\hline \multirow[t]{3}{*}{ Feeding $n=40$} & Male & 14 & $35 \%$ \\
\hline & Female & 9 & $22.5 \%$ \\
\hline & Both & 17 & $42.5 \%$ \\
\hline \multirow[t]{3}{*}{ Pond maintenance $n=40$} & Male & 28 & $70 \%$ \\
\hline & Female & 3 & $7.5 \%$ \\
\hline & Both & 9 & $22.5 \%$ \\
\hline \multirow[t]{3}{*}{ Monitoring fish growth $n=40$} & Male & 23 & $57.5 \%$ \\
\hline & Female & 6 & $15 \%$ \\
\hline & Both & 11 & $27.5 \%$ \\
\hline \multirow[t]{3}{*}{ Harvesting $n=40$} & Male & 6 & $15 \%$ \\
\hline & Female & 1 & $2.5 \%$ \\
\hline & Both & 33 & $82.5 \%$ \\
\hline \multirow[t]{3}{*}{ Processing $n=40$} & Male & 7 & $17.5 \%$ \\
\hline & Female & 1 & $2.5 \%$ \\
\hline & Both & 32 & $80 \%$ \\
\hline \multirow[t]{3}{*}{ Marketing $n=40$} & Male & 9 & $22.5 \%$ \\
\hline & Female & 8 & $20 \%$ \\
\hline & Both & 23 & $57.5 \%$ \\
\hline \multirow[t]{3}{*}{ Record keeping $n=19$} & Male & 8 & $42 \%$ \\
\hline & Female & 9 & $47 \%$ \\
\hline & Both & 2 & $11 \%$ \\
\hline
\end{tabular}

\subsubsection{Women's participation and food security}

We investigated whether there was a correlation between the number of activities in aquaculture production ( $\max n=9$, see Table 7) that are performed solely by a man, solely by a woman, and with a women being responsible (either alone or equally with a man), and the household's degree of food security and dietary diversity score (Table 8). No significant correlations were found.

We also investigated whether there was a difference in HDDS and ELCSA scores between female and male CBAVC workers. Although females appear to have a

Table 8 Spearman correlations between gendered aquaculture production responsibilities, household dietary diversity score, and degree of food security (Escala Latino Americana y Caribina de higher dietary diversity score than males (Table 9), there was no significant difference between the two groups. The average degree of food insecurity was also very close, with no significant difference found between the two groups (Table 10).

\subsubsection{Women's participation and income}

We investigated if there was a correlation between the number of activities that women and men performed on their own, with household net income from aquaculture, the size of aquaculture operations as measured by $\mathrm{m}^{2}$ of pond surface, and the

seguridad allimentaria scale of $0-3 ; 0=$ food secure, $1=$ mild, $2=\bmod -$ erate, $3=$ severe)
Activities are performed solely by a man

Degree of food security (ELCSA)

Dietary diversity (HDDS)

$-0.19(p=0.25)$

$0.18(\mathrm{p}=0.27)$
Activities are performed solely by a woman

$-0.06(p=0.71)$

$-0.21(p=0.21)$
Activities where a woman is involved

$0.14(p=0.4)$

$-0.06(p=0.69)$ 
Table 9 Details of household dietary diversity scores of central Bolivian aquaculture value chain workers according to gender

\begin{tabular}{lllll}
\hline & Mean & Median & St. Dev. & C.V. \\
\hline Female workers $\mathrm{n}=16$ & 7.69 & 8 & 1.25 & $16.3 \%$ \\
Male workers $\mathrm{n}=10$ & 7.10 & 7 & 1.37 & $19.3 \%$ \\
Mann-Whitney $\mathrm{U}=54(p=0.24)$ & & & \\
\hline
\end{tabular}

productivity of aquaculture operations as measured by income per $\mathrm{m}^{2}$ of pond area (Table 11). For women, no significant correlations were found. For men, significant and negative correlations were found between the number of activities they performed and both net income and productivity.

To investigate the impact of women's participation in aquaculture production, we explored the correlations between the number of tasks that a woman was responsible for, either alone or equally with a male household member, and net income (Fig. 13), size of operation (Fig. 14), and productivity (Fig. 15). Moderately strong and significant correlations were found for net income and productivity. Size of operation was weakly and insignificantly correlated but was very close to being moderate and significant. This indicates that households where women are involved in managing aquaculture operations are likely to be more successful than households that rely on just women, and especially more than households that rely on just men.

We also investigated whether women's hourly wages were significantly less than those of men who were working in the CBAVC (Table 12). A Mann-Whitney U test revealed women do make significantly less than men, with men making 55\% more on average per hour than women.

This difference in income is likely partially due to the positions that each gender tends to occupy. Men often work for input businesses that are large and which tend to pay higher salaries. They are also more likely to be employed in jobs that are physically demanding. Women tend to work at markets and restaurants, which are generally low-paying, and also less physically demanding. That said, these employers tend to be quite accommodating for childcare, and it is common for women to bring their children to work. Restaurants also occarsionally provide workers room and board in addition to

Table 10 Details of household degree of food insecurity (based on Escala Latino Americana y Caribina de seguridad alimentaria) of central Bolivian aquaculture value chain workers according to gender

\begin{tabular}{lclll}
\hline & Mean & Median & St. Dev. & C.V. \\
\hline Female workers $n=16$ & 1.38 & 1.5 & 0.89 & $65 \%$ \\
Male workers $n=10$ & 1.4 & 1.0 & 0.84 & $60 \%$ \\
Mann-Whiney $U=75(p=0.8)$ & & & \\
\hline
\end{tabular}

wages. Nonetheless, culture is likely a key factor that contributes to the large difference in hourly wages.

\section{Discussion}

South America is viewed as a "suitable underutilized site" for aquaculture (Anderson et al. 2017, p163), especially for inland production systems (Valladao et al. 2016). With this potential, and a growing domestic market, Latin American aquaculture output is expected to increase by more than $100 \%$ from 2010 levels by 2030 (Kobayashi et al. 2015). However, despite this overall potential, South American aquaculture and its contribution to livelihoods and food security is diverse, as is its interaction with local cultures. Aquaculture for export products (salmon, shrimp, mussels, and tilapia), grown at industrial levels, represents the greatest volume and value in the continent, but smaller scale farm-diversification approaches, generally serving local markets, are those promoted in development projects. These are variably promoted as improving livelihoods for the poor and/or introduction of healthy protein to local diets. Vasques and Flores-Nava (2014) describe these as Aquaculture of Limited Resources (AREL) and Aquaculture of Small and Medium Business (AMYPE). The first of these includes subsistence level aquaculture to primarily supplement household diets. Most research on the food security and social impacts of aquaculture have focused on the export-oriented systems or small-scale subsistence systems (Bush et al. 2019). Recent evidence suggests, however, that AMYPE type systems are responsible for a much larger share of aquaculture fish production, trade, and consumption around the world than previously thought, but are under-researched (Belton et al. 2018a; Bush et al. 2019).

Early efforts to establish Bolivian tropical aquaculture included AREL approaches with communal production, which did not generally persist after the loss of international subsidies. In part, this could be due to the traditionally low level of fish consumption in the target areas, as well as problems of communal ownership where it is not otherwise common (MDRyTViceMinisterio-IPD PACU 2014). Support of small business approaches in the AMYPE class has shown more sustainability and is likely responsible for the current growth of aquaculture (ibid.). We evaluated the contribution this emerging small-scale industry is having on local food security.

This aquaculture system of central Bolivia (the CBAVC) has both differences and similarities with the production and consumption systems found in other contexts such as Africa and Asia, reflecting its relative youth. Production occurs at the household level, is small to medium sized in scale, is primarily commercially oriented, and serves local and domestically regional markets. Household consumption occurs, but income generation is the primary purpose of production. Consumers 
Table 11 Spearman correlations between the number of tasks men and women do alone, and aquaculture net income, size of operation, and productivity

\begin{tabular}{lll}
\hline & $\begin{array}{l}\text { Number of tasks performed solely by a } \\
\text { woman }\end{array}$ & $\begin{array}{l}\text { Number of tasks performed solely by a } \\
\text { man }\end{array}$ \\
\hline $\begin{array}{l}\text { Net Income } \\
\begin{array}{c}\text { Size of } \\
\text { operation }\end{array}\end{array}$ & $r_{s}=-0.16(p=0.32)$. & $r_{s}=-0.40(p=0.01)$ \\
Productivity & $r_{s}=0.18(p=0.26)$ & $r_{s}=-0.26(p=0.11)$ \\
\hline
\end{tabular}

access aquaculture fish from local markets, restaurants, and occasionally directly from producers.

We focused on three pathways between aquaculture and food security outlined by Kawarazuka and Bene (2010); fish consumption, income, and women's participation. We found that food insecurity was widespread and did not differ in a statistically significant way between the three respondent groups - aquaculture producers, CBAVC workers, and nonaquaculture producing farmers. However, a trend towards greater food security amongst aquaculture producers was observed and may become stronger as their time engaged in aquaculture increases. The primary source of food insecurity amongst all three groups was anxiety over future access to food. These findings fit with the prevailing socio-economic conditions in Bolivia. There is a degree of social and economic stability and access to employment that provides access to food, but it is not sufficiently stable to alleviate concerns over future access to food (de Sousa et al. 2019; Ministry of Rural Development 2014; Salazar et al. 2016).

With respect to consumption, all three interviewed groups had reported consuming fish from aquaculture. Producers in particular reported high rates of fish consumption, a finding consistent with research on small-scale aquaculture production in Malawi (Dey et al. 2007), Bangladesh (Ahmed and Waibel 2019; Belton and Azad 2012), and various other Asian countries (Dey et al. 2005). CBAVC workers are also accessing farmed fish. This is likely because many workers, particularly restaurant and market workers and farm labourers, have easier access to fish than the average person. However, they often have to purchase the fish they consume, unlike producers, which explains their relatively lower consumption rate. Nonaquaculture farmers also had high rates of fish consumption, including fish from aquaculture. This indicates that aquaculture is improving the availability of fish in the region, including for those who face economic challenges, and is having an impact on the generally low average levels of Bolivian fish consumption. For the poorest of the poor, who tend to be landless, the change in their access to fish is unclear, but given the growing ubiquity of fish in the region, it is likely improving to some degree. This is promising for development practitioners since concerns have been raised about aquaculture's capacity to reach poorer consumers (Beveridge et al. 2013).

Despite the growth of the CBAVC and widespread fish consumption, dietary diversity varied little between groups, with the exception of high fish consumption amongst producers and high fruit consumption amongst non-aquaculture farmers. Households not only ate similar foods, but they tended to eat the same simple dishes, even with higher incomes and even in restaurants. This indicates strong cultural resistance to dietary change. The relatively stable variance in the HDDS index (as $\mathrm{CV})$, rather than increasing with increased income, may also be due to dietary resilience, as observed by Maxwell et al. (2013). Nevertheless, fish are adequately consumed and sought after, indicating there may be unsatisfied demand. This is not fully addressed by the current aquaculture output, probably in part because of the price. Our results indicate that the demand for
Fig. 13 Relationship between net household income from aquaculture and the number of aquaculture activities a woman performs, either alone or in partnership with a male household member

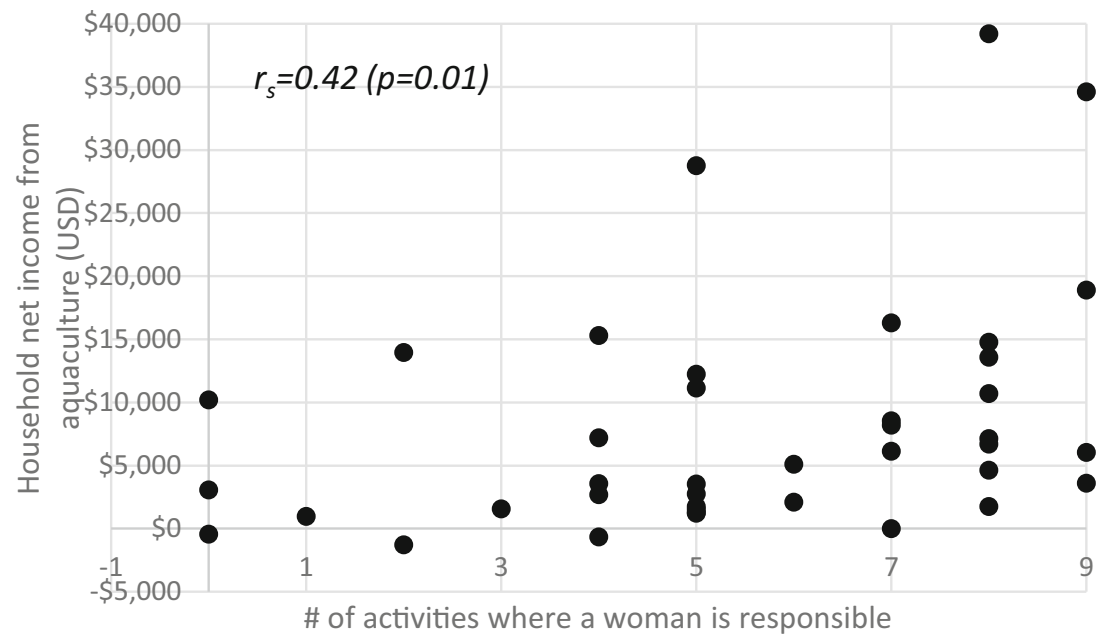


Fig. 14 Relationship between size of aquaculture operation $\left(\mathrm{m}^{2}\right)$ and the activities a woman performs, either alone or in partnership, with a male household member

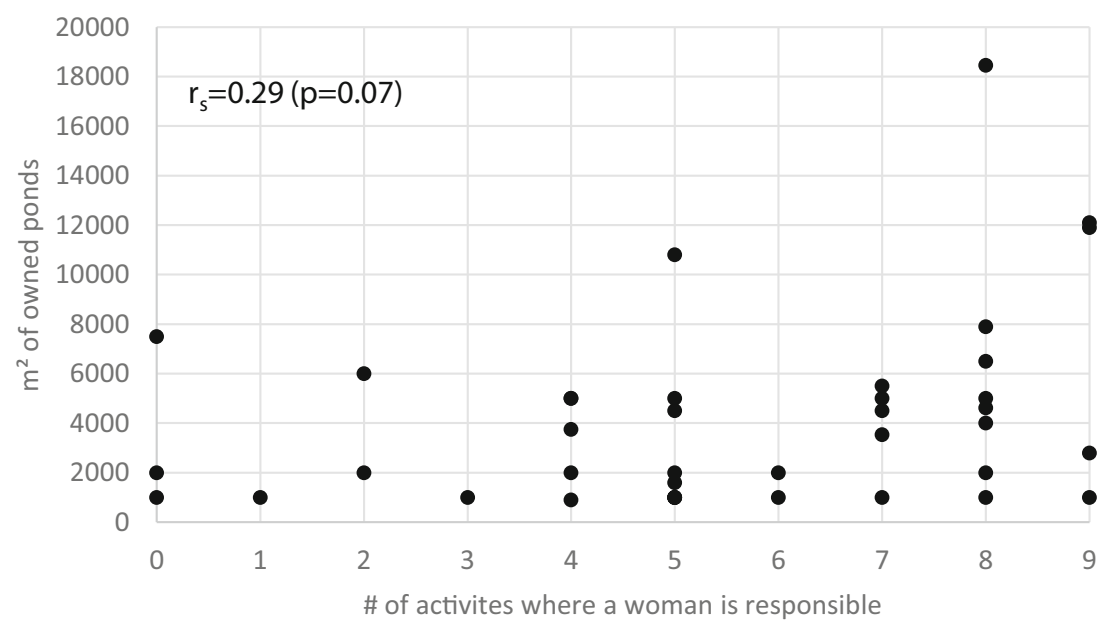

fish is based on its taste, with little knowledge of its superior nutritional value. Educational marketing of the nutritional value of fish appears to be a largely untapped avenue. Improving fish consumption with aquaculture production will need to consider species that have cultural recognition, good perceived taste, and are more economical. There is evidence that fish farming can diversify diets elsewhere, either by generating income that can be spent on other food (Aiga et al. 2009; Ahmed and Waibel 2019) or by changing cooking habits (Thilsted 2012). However, the homogeneity in food preferences, as in this Bolivian location, is an important consideration for development interventions seeking to bolster local food security by introducing more nutritious foods.

Net aquaculture income was weakly and insignificantly correlated with better food security, but a positive trend was observed. Non-aquaculture producer gross income was moderately and significantly correlated with better food security. Aquaculture producers were also wealthier on average than non-producers and chain workers. These findings indicate that although food insecurity is widespread, income has a modest positive effect on improving food security. The CBAVC also generates employment, but variations in income from that employment did not correlate to variations in food security. This is likely because almost all work in the chain is low paying. However, it was reported as being moderately better than alternatives, implying a small positive impact. Studies in Myanmar (Filipski and Belton 2018) and Ghana (Kassam and Dorward 2017) showed similar findings. Future research that compares CBAVC workers to other food value chain workers could determine if that impact translates to improved food security.

A key question in the aquaculture literature is whether AMYPE aquaculture production is accessible to lower income segments of rural society, or only to higher capacity producers that can afford the entry costs of land and infrastructure (Bene et al. 2016). Barriers to entering pacu or tambaqui farming in central Bolivia are relatively low for households that already own land. Since individual land ownership is widespread and many landowners struggle economically in the region (Andersen 2018), aquaculture can be a viable pathway to household income and food security for rural Bolivians. This contrasts with other contexts where aquaculture is only accessible to wealthier producers. To what degree this holds as the system grows is unknown, but recent research by Belton et al. (2018b) in Myanmar and Gonzalez-Poblete et al. (2018) in Chile suggests
Fig. 15 Relationship between net aquaculture income per $\mathrm{m}^{2}$ of stocked pond and the number of aquaculture activities a woman performs, either alone or in partnership with a male household member

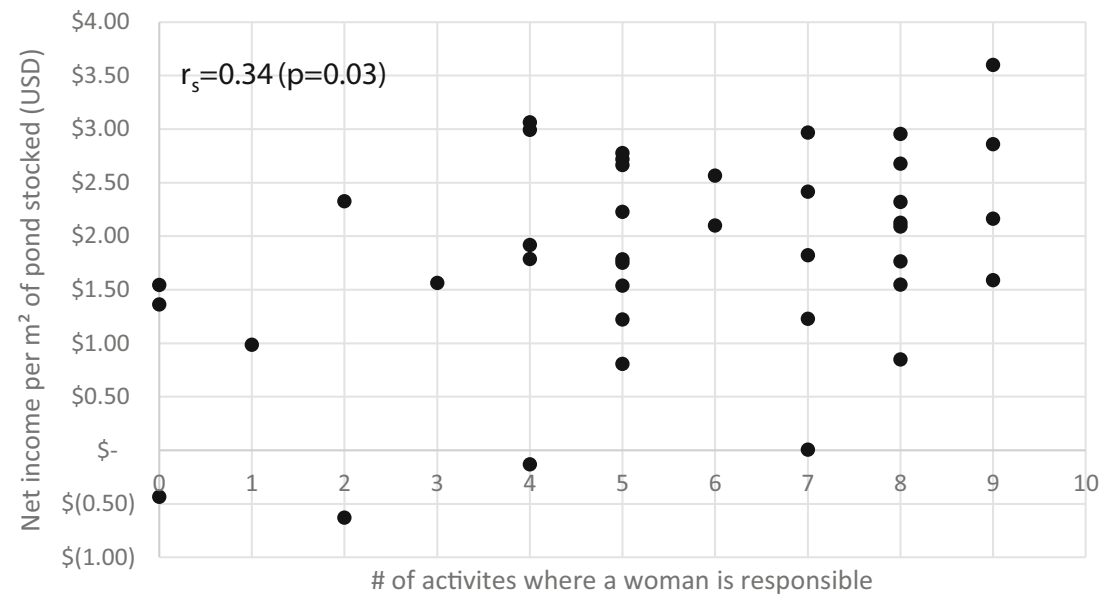


Table 12 Details of central Bolivian aquaculture value chain worker hourly income by gender

\begin{tabular}{lllll}
\hline & Average hourly wage (USD) & Median & Standard deviation & Coefficient of variation \\
\hline Women & $\$ 1.03$ & $\$ 0.77$ & $\$ 0.79$ & $77 \%$ \\
Men & $\$ 1.60$ & $\$ 0.77$ & $\$ 0.65$ & $41 \%$ \\
Mann-Whiney $\mathrm{U}=175.5(p=0.04)$ & & & \\
\hline
\end{tabular}

that even if large scale aquaculture operations were to emerge in central Bolivia, they may do so alongside, rather than displace, the existing small and medium scale producers.

The connection between women's participation in aquaculture and food security has been shown (Jahan et al. 2010; Kawarazuka and Bene 2010; Monfort 2015) but is under researched (Brugere and Williams 2017; Gopal et al. 2020; Kruijssen et al. 2018). Women participate throughout the CBAVC, but unevenly. Production is undertaken more extensively by men, but male dominated operations were smaller, less productive, and generated less income than female dominated operations. However, the largest, most profitable, and most productive producer households were those where women were involved in aquaculture. Shirajee et al. (2010) similarly found that women's involvement in household aquaculture in Bangladesh increased production, but dissimilarly this was through their additional labour more than through co-operation. The CBAVC also generates employment opportunities for women, more so than for men. Barriers to access to CBAVC employment are low and employment is accessed by economically marginalized people, including women. However, CBAVC employment falls along Bolivian gender norms, which under-value women, especially indigenous women (Grown and Lundwall 2016). Positions occupied by women are lower paying on average compared to men's employment, a common finding in other contexts (Kruijssen et al. 2013; Veliu et al. 2009). The division of labour in Bolivia is similar to that found by Ndanga et al. (2013) in Western Kenya, where women participate in production and marketing, but it is different in terms of profitability - in Kenya working in markets is more profitable than production, in Bolivia production is more profitable than retail work. Overall, women are occupying roles in the CBAVC which is contributing to food security, but this varies based on the role - worker or producer and on the degree of participation.

\section{Conclusion and recommendations}

The rapid growth and diversification of aquaculture is having an increasingly large impact on global food security. At the national level, however, this impact is highly uneven due to large differences in social, ecological, cultural, and political contexts. This article investigated the impact small-scale commercially oriented aquaculture has had on the food security of aquaculture value chain actors along three pathways: consumption, income, and women's participation. Our results indicate that the introduction and growth of aquaculture increased regional fish consumption, thereby generating a positive nutritional impact, but not due to knowledge of beneficial nutrition, and limited by conservative dietary preferences, access, and cost. The presence of the CBAVC did not have a significant effect on otherwise diversifying the diets of the respondents. Development practitioners seeking to improve food security and nutrition in a region by introducing a new food, should do so as part of a comprehensive socially and culturally aware strategy. In addition to providing information on the economic benefits of fish farming, there is also a need to disseminate information on fish preparation and healthy eating.

Aquaculture is generating income and employment, which in turn is having a modest positive effect on food security. Fish farming appears to be a better income generator than other farm-based livelihoods in the region. Greater investment by both national and local governments in training and infrastructure will pay dividends in terms of achieving higher incomes and improved food security.

Women participate in many farm level fish production activities. As their involvement increases farms tend to become larger, more productive, and more profitable. Interestingly, male dominated aquaculture, by contrast, is negatively correlated with growth, productivity, and profitability. Women are also gaining employment in the value chain, but such employment is low paying. This situation could be improved if training and extension services were to be offered by government agencies and/or NGOs. There is a need, however, to broaden the focus from that of simply increasing the number of women participating in the CBAVC, to ensuring the adoption of gender sensitive approaches in their training programs to make them more readily accessible and inclusive for women. There is also a need to directly address gender-based income discrepancies. Together, these initiatives would help to ensure that women benefit more fully from growth in the aquaculture sector, and in turn, the sector would benefit from their greater participation.

Acknowledgements The Canadian International Food Security Research Fund, the International Development Research Centre (IDRC), and Global Affairs Canada funded this study. Thanks are also extended to Veronica Hijinosa and Widen Abastiflora of the Centro de Promoción Agropecuaria Campesina (CEPAC), Luis Enrique Badani and Alvaro Luis Céspedes Ramirez of Ingenieria Marketing Gestión (IMG) for valuable collaboration and logistical support, to Juan Siancas for organizing and facilitating the interviews, and to Thomas Giguére for assistance with statistical analysis. We are also grateful for the time and effort of two anonymous reviewers and the editors at Food Security whose constructive feedback helped us significantly improve this paper. 


\section{Compliance with ethical standards}

Conflict of interest The authors declare that they have no conflict of interest.

Open Access This article is licensed under a Creative Commons Attribution 4.0 International License, which permits use, sharing, adaptation, distribution and reproduction in any medium or format, as long as you give appropriate credit to the original author(s) and the source, provide a link to the Creative Commons licence, and indicate if changes were made. The images or other third party material in this article are included in the article's Creative Commons licence, unless indicated otherwise in a credit line to the material. If material is not included in the article's Creative Commons licence and your intended use is not permitted by statutory regulation or exceeds the permitted use, you will need to obtain permission directly from the copyright holder. To view a copy of this licence, visit http://creativecommons.org/licenses/by/4.0/.

\section{References}

Ahmed, B., \& Waibel, H. (2019). The role of homestead fish ponds for household nutrition security in Bangladesh. Food Security, 11, 835 854

Aiga, H., Matsuoka, S., Kuroiwa, C., \& Yamamoto, S. (2009). Malnutrition among children in rural Malawian fish-farming households. Transactions of the Royal Society of Tropical Medicine and Hygiene, 103(8), 827-833.

Allen, S., \& de Brauw, A. (2018). Nutrition sensitive value chains: Theory, progress, and open questions. Global Food Security, 16, 22-28.

Andersen, L. (2018). ¿Dónde están los bolivianos extremadamente pobres? INESAD: Desarrollo sobre la mesa. Available at: https:// inesad.edu.bo/dslm/2018/02/donde-estan-los-bolivianosextremadamente-pobres/

Anderson, J., Asche, F., Garlock, T. \& Chu, J. (2017). Aquaculture: Its role in the future of food, in Schmitz, A., Kennedy, P. \& Schmitz, T. Frontiers of economics and globalization Vol. 17: World Agricultural Resources and Food Security, International Food Security, Emerald Pub.: Bingley, UK.

Belton, B., \& Azad, A. (2012). The characteristics and status of pond aquaculture in Bangladesh. Aquaculture, 358, 196-204.

Belton, B., Hein, A., Htoo, K., Kham, L., Nischan, U., Reardon, T. \& Boughton, D. (2015). Aquaculture in transition: Value chain transformation, fish and food security in Myanmar. Feed the future innovation lab for food security policy, research paper 8 .

Belton, B., Bush, S., \& Little, D. (2018a). Not just for the wealthy: Rethinking farmed fish consumption in the global south. Global Food Security, 16, 85-92.

Belton, B., Hein, A., Htoo, K., Kham, L., Phyoe, A., \& Reardon, T. (2018b). The emerging quiet revolution in Myanmar's aquaculture value chain. Aquaculture, 493, 384-394.

Bene, C., Barange, M., Subasinghe, R., Pinstrup-Andersen, P., Merino, G., Hemre, G., \& Williams, M. (2015). Feeding 9 billion by $2050-$ Putting fish back on the menu. Food Security, 7, 261-274.

Bene, C., Arthur, R., Norbury, H., Allison, E., Beveridge, M., Bush, S., et al. (2016). Contribution of fisheries and aquaculture to food security and poverty reduction: Assessing the current evidence. World Development, 79, 177-196.

Beveridge, M., Thilsted, S., Phillips, M., Metian, M., Troell, M., \& Hall, S. (2013). Meeting the food and nutrition needs of the poor: The role of fish and the opportunities and challenges emerging from the rise of aquaculture. Journal of Fish Biology, 83, 1067-1084.
Brugere, C. \& Williams, C. (2017). Profile: Women in aquaculture. Available at: https://genderaquafish.org/portfolio/women-inaquaculture/

Bush, S., Belton, B., Little, D., \& Islam, M. (2019). Emerging trends in aquaculture value chain research. Aquaculture, 498, 428-434.

Camburn, M. (2011). El consumo de pescado en la Amazonía Boliviana. FAO: Rome.

Canal-Beeby, E. (2012). Aquaculture and rural livelihoods in the Bolivian Amazon - Systems of Innovation and pro-poor technology development. $\mathrm{PhD}$ thesis: $\mathrm{U}$ of East Anglia.

Coates, J., Swindale, A. \& Bilinsky, P. (2007). Household insecurity access scale (HFIAS) for measurement of food access: Indicator guide.

de Sousa, L., Saint-Ville, A., Samayoa-Figueroa, L., \& MelgarQuinonez, H. (2019). Changes in food security in Latin America from 2014-2017. Food Security, 11, 503-513.

Dey, M., Rab, M., Paraguas, F., Piumsombun, S., Bhatta, R., Alam, M., et al. (2005). Fish consumption and food security: A disaggregated analysis by types of fish and classes of consumers in selected Asian countries. Aquaculture Economics and Management, 9(1-2), 89111.

Dey, M., Kambewa, P., Prein, M., Jamu, D., Paraguas, F., Pemsl, D., \& Briones, R. (2007). Impact of the development and dissemination of integrated aquaculture-agriculture technologies in Malawi. In $\mathrm{H}$. Waibel \& D. Zilberman (Eds.), International research on natural resource management: Advances in impact assessments (pp. 118 146). Wallingford: CABI International.

Donovan, J., Franzel, S., Cunha, M., Gyau, A., \& Mithöfer, D. (2015). Guides for value chain development: A comparative review. Journal of Agribusiness in Developing and Emerging Economies, $5(1), 2-23$

EIU (Economist Intelligence Unit). (2018). Global food security index. Available at: https://foodsecurityindex.eiu.com/Index

ELCSA. (2012). Escala Latino Americana y Caribina de seguridad allimentaria (ELCSA): Manual de uso y applicaciones. Rome: FAO.

Fanzo, J., Downs, S., Marshall, Q., de Pee, S., \& Bloem, M. (2017). Value chain focus on food and nutrition security. In S. de Pee, D. Taren, \& M. Bloem (Eds.), Nutrition and health in a developing world. Cham: Humana Press.

FAO. (2005). National Aquaculture Sector Overview - Bolivia. Rome: FAO Available at: http://www.fao.org/fishery/countrysector/naso bolivia/en.

FAO. (2020). The state of world fisheries and aquaculture 2020. Sustainability in action. Rome: FAO.

Filipski, M., \& Belton, B. (2018). Give a man a fishpond: Modeling the impacts of aquaculture in the rural economy. World Development, 110, 205-223.

Garlock, T., Asche, F., Anderson, J., Bjørndal, T., Kumar, G., Lorenzen, K., Ropicki, A., Smith, M., \& Tveterås, R. (2020). A global blue revolution: Aquaculture growth across regions, species, and countries. Reviews in Fisheries Science \& Aquaculture, 28(1), 107-116.

Global Hunger Index. (2018). Bolivia. Available at: https://www. globalhungerindex.org/bolivia.html

Gonzalez-Poblete, E., Ferreira, F., Silva, C., \& Cleveland, R. (2018). Blue mussel aquaculture in Chile: A small or large scale industry? Aquaculture, 493, 113-122.

Gopal, N., Hapke, H., Kusakabe, K., Rajaratnam, S., \& Williams, M. (2020). Expanding the horizons for women in fisheries and aquaculture. In Expanding the horizons for women in fisheries and aquaculture. Technology and Development: Gender.

Grown, C., \& Lundwall, J. (2016). In Bolivia, being female and indigenous conveys multiple disadvantages. In World bank blogs Available at: https://blogs.worldbank.org/voices/bolivia-beingfemale-and-indigenous-conveys-multiple-disadvantages. 
Instituto Nacional de Estadística de Bolivia (INE). (2014). Un pincelazo a las estadisticas con base a datos de censos censo nacional agropecuario, 2013 Available at: http://www.ine.gob.bo.

Jahan, K., Ahmed, M., \& Belton, B. (2010). The impacts of aquaculture development on food security: Lessons from Bangladesh. Aquaculture Research, 41(4), 481-495.

Kassam, L., \& Dorward, A. (2017). A comparative assessment of the poverty impacts of pond and cage aquaculture in Ghana. Aquaculture, 470, 110-122.

Kawarazuka, N., \& Bene, C. (2010). Linking small-scale fisheries and aquaculture to household nutritional security: An overview. Food Security, 2(4), 343-357.

Kennedy, G., Ballard, T., \& Dop, M. (2011). Guidelines for measuring household and individual dietary diversity. International Journal of Food Safety, Nutrition and Public Health, 2.

Kobayashi, M., Msangi, S., Batka, M., Vannuccini, S., Dey, M., \& Anderson, J. (2015). Fish to 2030: The role and opportunity for aquaculture. Aquaculture Economics \& Management, 19(3), 282300.

Kruijssen, F., Albert, J., Morgan, M., Boso, D., Siota, F., Sibiti, S., \& Schwarz, A. (2013). Livelihoods, markets, and gender roles in Solomon Islands: Case studies from Western and Isabel provinces. Penang, Malaysia: CGIAR Research Program on Aquatic Agricultural Systems.

Kruijssen, F., McDougall, C., \& van Asseldonk, I. (2018). Gender and aquaculture value chains: A review of key issues and implications for research. Aquaculture, 493, 328-337.

Marinda, P., Genschick, S., Khayeka-Wandabwa, C., KiwanukaLubinda, R., \& Thilsted, S. (2018). Dietary diversity determinants and contribution of fish to maternal and under-five nutritional status in Zambia. PLoS One, 13(9), e0204009.

Maxwell, D., Coates, J., \& Vaitla, B. (2013). How do different indicators of household food security compare? Empirical evidence from Tigray. Medford, USA: Feinstein International Center, Tufts University.

MDRyT-ViceMinisterio-IPD PACU. (2014). Acuicultura boliviana: Lineamientos estratégicos para el desarrollo de la piscicultura tropical en Bolivia (84 p). Editorial INIA, Bolivia: IPD PACU.

Metian, M., Troell, M., Christensen, V., Steenbeek, J., \& Pouil, S. (2020). Mapping diversity of species in global aquaculture. Reviews in Aquaculture., 1-11.

Ministry of Rural Development and Land, Bolivia. (2014). Plan del Sector-Sector Desarrollo Agropecuario 2014-2018, "Hacia el 2025". Dirección General de Planificación.

Mohanty, B., Mahanty, A., Ganguly, S., Mitra, T., Karunakaran, D., \& Anandan, R. (2017). Nutritional composition of food fishes and their importance in providing food and nutritional security. Food Chemistry, 293, 561-570.

Monfort, M. (2015). The role of women in the seafood industry. GLOBEFISH research Programme, Vol. 119. FAO: Rome.

Murthy, L., Madhusudana, B., Asha, K., \& Prasad, M. (2015). Nutritional composition, product development, shelf-life evaluation and quality assessment of pacu Piaractus brachypomus (Cuvier, 1818). Indian Journal of Fish, 62(1), 101-109.

Ndanga, L., Quagrainie, K., \& Dennis, J. (2013). Economically feasible options for increased women participation in Kenyan aquaculture value chain. Aquaculture, 414, 183-190.

Neuman, W. (2006). Social research methods: Qualitative and quantitative approaches (6th ed.). Boston, MA: Pearson Education Inc..

PPV2 (Peces Para la Vida 2). (2017). Boletin informative No. 4. Available at: http://www.pecesvida.org/publicaciones/boletines

Petenuci, M., Rocha, L., de Sousa, S., Schneider, V., da Costa, L., \& Visentainer, J. (2016). Seasonal variations in lipid content, fatty acid composition and nutritional profiles of five freshwater fish from the Amazon basin. Journal of the American Oil Chemists Society, 93, 1373-1381.
Ponte, S., Kelling, I., Jespersen, K., \& Kruijssen, F. (2014). The blue revolution in Asia: Upgrading and governance in aquaculture value chains. World Development, 64, 52-64.

Rapsomaniskis, G. (2015). The economic lives of smallholder farmers: An analysis based on household data from nine countries. FAO: Rome.

Salazar, L., Aramburu, J., Gonzalez-Flores, M., \& Winters, P. (2016). Sowing for food security: A case study of smallholder farmers in Bolivia. Food Policy, 65, 32-52.

Shirajee, S., Salehin, M., \& Ahmed, N. (2010). The changing face of women for small-scale aquaculture development in rural Bangladesh. Aquaculture Asia Magazine, 15(2), 9-16.

Swindale, A., \& Bilinsky, P. (2006). Household dietary diversity score (HDDS) for measurement of household food access: Indicator guide: Version 2. FANTA Project; USAID.

Tacon, A. (2020). Trends in global aquaculture and Aquafeed production: 2000-2017. Reviews in Fisheries Science \& Aquaculture, 28(1), $43-56$.

Telesur. (2017). Bolivia slashes chronic malnutrition in children by nearly 50 percent. Available at: https://www.telesurenglish.net/news/ Bolivia-Slashes-Chronic-Malnutrition-in-Children-by-Nearly-50Percent-20170907-0033.html

Thilsted, S. (2012). The potential of nutrient-rich small fish species in aquaculture to improve human nutrition and health. In R.P. Subasinghe, J.R. Arthur, D.M. Bartley, S.S. De Silva, M. Halwart, N. Hishamunda, C.V. Mohan \& P. Sorgeloos (Eds.), Farming the Waters for People and Food. Proceedings of the Global Conference on Aquaculture 2010, Phuket, Thailand (pp. 57-73), September 22$25,2010$.

Thilsted, S., Thorne-Lyman, A., Webb, P., Bogard, J., Subasingh, R., Phillips, M., \& Allison, E. (2016). Sustaining healthy diets: The role of capture fisheries and aquaculture for improving nutrition in the post-2015 era. Food Policy, 61, 126-131.

Valladao, G., Gallani, S., \& Pilarski, F. (2016). South American fish for continental aquaculture. Reviews in Aquaculture, 10(2), 351-369.

Van Damme, P., Salas, R., Perez, T., Rada, C., MacNaughton, A., Rainville, T. \& Carolsfeld, J. (2014). Food security, fisheries, and aquaculture in the Bolivian Amazon. IDRC project 106524-003, final project report.

Vasques, H., \& Flores-Nava, A. (2014). Acuicultura de pequena escala y recursos limitados en America Latina y el Caribe: Hacia un enfoque integral de politicas publicas. Red de Acuicultura de las Americas: FAO.

Vega, B., Lobo, F., Zubieta, J., Carolsfeld, J., Zambrana, I., \& Van Damme, P. (2018). Socio-environmental mapping for the prediction of aquaculture success of Pacu (Colossoma spp., Piaractus spp., and hybrids) in the Bolivian Amazon. Journal of Applied Ichthyology, 34(6), 1267-1276.

Veliu, A., Gessese, N., Ragasa, C., \& Okali, C. (2009). Gender analysis of the aquaculture value chain in Northeast Vietnam and Nigeria. In Agriculture and rural development discussion paper 44. The World Bank: Washington.

World Bank. (2018). World Bank data: Bolivia. Available at: https://data. worldbank.org/country/bolivia

World Bank. (2019a). Bolivia at-a-glance. Available at: https://www. worldbank.org/en/country/bolivia

World Bank. (2019b). Prevalence of stunting, height for age (\% of children under 5). Available at: https://data.worldbank.org/indicator/ SH.STA.STNT.ZS ?locations $=\mathrm{BOb}$

World Food Programme. (2018). Bolivia country strategic plan 20182022. Available at: https://www1.wfp.org/operations/bo02-boliviacountry-strategic-plan-2018-2022 


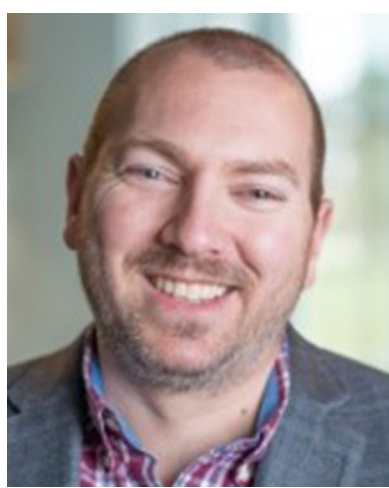

Sean Irwin is an Assistant Professor in the School of Business at Royal Roads University, Victoria, BC, Canada. Sean's research investigates the intersection of food systems and socio-economic development as a means to address the interconnected problems of future global food needs and reducing rural poverty. His primary methodological interest is using mixed methods to investigate the social and economic functioning of value chains. His research has focused on food security, gender equality, the effects of international trade and globalization on small-scale farmers, and the environmental impact of food systems. His geographic focus is Latin America, with past research experience in rural Belize, and more recently, the Amazonian region of Bolivia. Sean holds a $\mathrm{PhD}$ in Geography from the University of Victoria

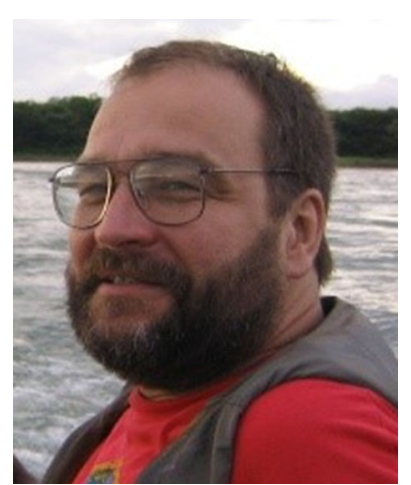

Joachim Carolsfeld is the Executive Director of World Fisheries Trust, Victoria, BC, Canada. He has over 25 years experience in the non-profit sector and has worked around the world on fisheries and aquaculture development. His research is focused on community development and poverty alleviation through sustainable use of fish resources. Joachim holds a $\mathrm{PhD}$ in fish reproductive physiology from the University of Victoria, Victoria, BC, Canada.

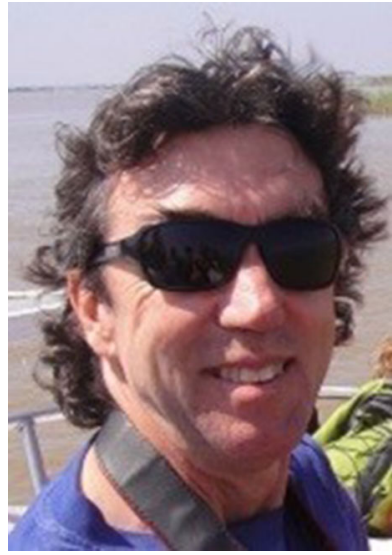

Mark S. Flaherty is a Professor in the Department of Geography at the University of Victoria, Victoria, BC, Canada. Mark's research interest is on the role that small-scale fisheries and aquaculture can play in improving food security and reducing poverty in the developing world. Past projects have been in Thailand, India, and Mozambique. He is also interested in multi-trophic aquaculture in Canada, and the perspectives of coastal communities, with an emphasis on First Nations. Mark holds a PhD in geography from McMaster University. 